\title{
Analytical, toxicological and kinetic investigation of decomposition of the drug diclofenac in waters and wastes using gamma radiation
}

\author{
A. Bojanowska-Czajka ${ }^{1}$ - G. Kciuk ${ }^{1} \cdot$ M. Gumiela ${ }^{1}$ - S. Borowiecka ${ }^{2}$. \\ G. Nałęcz-Jawecki ${ }^{3}$ - A. Koc ${ }^{2}$ - J. F. Garcia-Reyes ${ }^{4}$ - D. Solpan Ozbay ${ }^{5}$ • \\ M. Trojanowicz ${ }^{1,2}$
}

Received: 5 May 2015 / Accepted: 11 August 2015 /Published online: 27 August 2015

(C) The Author(s) 2015. This article is published with open access at Springerlink.com

\begin{abstract}
The radiolytic decomposition of the drug diclofenac (DCF), and in limited extent, also two other widely used drugs, ibuprofen and carbamazepine, was examined using liquid chromatography (LC) methods. The efficiency of DCF decomposition was examined in function of the absorbed dose of gamma radiation, and also in the presence of selected scavengers of radicals, which are commonly present in natural waters and wastes. Three different tests were employed for the monitoring of toxicity changes in the irradiated DCF solutions. The LC/ mass spectrometry (MS) was used for the determination of products of DCF radiolysis. Using pulse-radiolysis method with the spectrophotometric detection, the rate constant values were determined for reactions of DCF with the main products of water radiolysis: hydroxyl radicals $(1.24 \pm 0.02) \times$ $10^{10} \mathrm{M}^{-1} \mathrm{~s}^{-1}$ and hydrated electrons $(3.1 \pm 0.2) \times 10^{9} \mathrm{M}^{-1} \mathrm{~s}^{-1}$. Their values indicate that both oxidative and reductive processes in radiolytic decomposition of DCF can take place in irradiated diluted aqueous solutions of DCF. The possibility of decomposition of all examined analytes was investigated in
\end{abstract}

Responsible editor: Hongwen Sun

A. Bojanowska-Czajka a.bojanowska@ichtj.waw.pl

1 Institute of Nuclear Chemistry and Technology, Dorodna 16, 03-195 Warsaw, Poland

2 Department of Chemistry, University of Warsaw, Pasteura 1, 02-093 Warsaw, Poland

3 Department of Environmental Health Sciences, Medical University of Warsaw, Warsaw, Poland

4 Faculty of Physical and Analytical Chemistry, University of Jaen, Jaen, Spain

5 Department of Chemistry, Hacettepe University, Ankara, Turkey samples of river water and hospital waste. Compared to the previous studies, the conducted measurements in real samples were carried out at the concentration levels, which are close to those reported earlier in environmental samples.

Keywords Diclofenac - Radiolytic decomposition · Pulse radiolysis $\cdot$ Toxicity monitoring

\section{Introduction}

The wide use of pharmaceuticals by the contemporary society unfortunately results in an important side effect, which is an increasing danger for the natural environment by pharmaceutical residues. The first reports about detecting pharmaceuticals in environmental samples were published in the early 1970s [Tabak et al. 1970], and in 1965, it was observed for the first time that residues of steroid hormones are not completely decomposed by wastewater treatment [StummZollinger, 1965]. Since then, a fast increase of interest in different aspects of the presence of pharmaceutical residues in environmental waters is observed. Number of papers published annually was about 500 in 2000 , while it reached the level of about 3000 in 2010 [Fatta-Kassinos et al. 2011]. In the recent decade, this problem was a subject of several published books, e.g., [Kümmerer 2008], and numerous valuable review articles in scientific journals, e.g., [Fatta-Kassinos et al. 2011, Mompelat et al. 2009, Luo et al. 2014].

A common presence of pharmaceutical residues in the aquatic environment, and also in finished drinking water, is a source of concern about their impact on public health, although a commonly encountered opinion in the literature is that our current knowledge about the effects of low-dose mixture of pharmaceuticals on human health is very limited. One 
can find opinions about no appreciable risk to humans at detected concentrations of pharmaceutical residues [Schulman et al. 2002], but due to consuming the contaminated drinking water over a lifetime, chronic toxic effects cannot be excluded because of a lack of chronic ecotoxicity data [Carlsson et al. 2006].

Pharmaceuticals disposed to the natural environment are very large and diverse group of chemicals consisting of both human and veterinary medicinal compounds. The main groups of pharmaceuticals, which are detected in aqueous environment include anti-inflammatory drugs (analgestics), steroids and related hormones, antibiotics, $\beta$-blockers, and lipid regulators. Some of them are consumed annually even in tens or hundreds of tons. For instance, the non-steroidal anti-inflammatory drug paracetamol, $622 \mathrm{t}$ in Germany in 2001; ibuprofen, $345 \mathrm{t}$ in Germany in 2001; diclofenac, $86 \mathrm{t}$ in Germany in 2001; and naproxen $35 \mathrm{t}$ in England in 2001 [Fent et al. 2006]. The trend of the continuous increase of consumption of pharmaceuticals can be illustrated e.g., for data on antidepressants consumption from 2000 to 2010 (OECD 2012). In all European countries for which data is available, the consumption of antidepressants has increased by over $80 \%$ on average across EU member states. In another example, the diclofenac consumption in Netherlands was evaluated as $2124 \mu \mathrm{g} / \mathrm{cap} /$ day in 2012, while in Germany already in 2003 as $2613 \mu \mathrm{g} /$ cap/day [Johnson et al. 2013].

As the main source of a wide presence of pharmaceuticals in the environment is considered, the municipal water discharge, of which drug residues are not completely removed by current wastewater processes. Other contributing sources are industries, farms and hospitals, although for instance, it was demonstrated recently by studies carried out in Norway that the point sources discharges from hospitals typically make a small contribution to the overall pharmaceutical load in comparison to municipal sources [Langford et al. 2009]. One of the most frequently detected pharmaceuticals in waters and urban wastes is diclofenac (DCF), which is 2-[(2,6dichlorophenylo)amino]benzene acetic acid, used mostly in form of sodium salt or methyl ester.<smiles>NC(=O)Cc1ccccc1Nc1c(O)cccc1Cl</smiles>

It is widely used in medical care as an analgestic, antiarthritic, and antirheumatic compound, belonging to the group of the non-steroidal anti-inflammatory drugs. Some $15 \%$ of DCF, however, is excreted unchanged after human uptake. It is used worldwide and has a production volume estimated to be in the hundreds of tons annually [Buser et al. 1998].
Among some ecotoxicological effects of the common presence of DCF in the environment, one can indicate e.g., histopathological alterations and bioaccumulation in fishes [Schwaiger et al. 2004], or a discovered vulture population decline in Pakistan [Oaks et al. 2004].

It is estimated that more than $90 \%$ of DCF is eliminated from waters by the photolytic degradation by natural sunlight; however, in recently proposed ranking system for all detected pharmaceuticals, the personal care products and endocrine disrupting chemicals in USA in surface and finished drinking waters, DCF was in 47th position in terms of overall score, and 48th position in terms of ecological effects [Kumar et al. 2010]. In the review on the environmental occurrence of pharmaceuticals, one can find that its content in surface waters may reach even $1.2 \mu \mathrm{g} / \mathrm{L}$, and in effluents $2.1 \mu \mathrm{g} / \mathrm{L}$ [Daughton et al. 1999], but also the level as high as $5.45 \mu \mathrm{g} / \mathrm{L}$ was reported in some effluents [Ferrari et al. 2003]. Concentration of some pharmaceuticals detected in effluents (antibiotics, non-steroidal anti-inflammatory drugs, or steroid hormones) may reach even fractions of milligrams per liter [Ikehata et al. 2006].

Besides increasing consumption of pharmaceuticals, a significant factor contributing to their presence in the environment is a limited efficiency of their decomposition in wastewater treatment plants, and in drinking water treatment plants. Data recently collected in the above-mentioned review [Luo et al. 2014], indicate only about $35 \%$ removal efficiency of diclofenac in the conventional wastewater treatment plants. This limited efficiency concerns also such methods as UV irradiation, oxidation with free chlorine, or even ozonation [Snyder 2008]. This is then reflected by concentrations of pharmaceuticals and their metabolites in worldwide tap water, which are found in some cases in the level exceeding $1 \mu \mathrm{g} / \mathrm{L}$ [Jones et al. 2005]. Hence, a strong attention is focused in recent years on the development of efficient radical methods of decomposition, described as advanced oxidation processes (AOPs). Especially efficient process is the radiolytic decomposition by the use of ionizing radiation ( $\gamma$ or beam of accelerated electrons, EB), where radicals of oxidative and reductive properties are formed as the result of the water radiolysis taking place during irradiation of a diluted aqueous solutions. These processes were already examined, e.g., for satisfactory decomposition of $\beta$-blockers [Song et al. 2008] and antibiotic nitroimidazoles [Sanchez-Polo et al. 2009].

In recent decade, a large attention is focused also on the development of various methods for removal of diclofenac from waters and wastes (Table 1), while effectiveness of removal of DCF in wastewater treatment plants was discussed in a separate review [Zhang et al. 2008]. Data showed in Table 1 indicate that majority of reported AOPs for the decomposition of DCF at $\mathrm{mg} / \mathrm{L}$ concentration level require relatively a long period of time. The exceptions are ozonation methods, although 
Table 1 Examples of the application of advanced oxidation processes and electro-oxidation for the decomposition of diclofenac

\begin{tabular}{|c|c|c|c|}
\hline Method & Initial DCF concentration, $\mathrm{mg} / \mathrm{L}$ & Efficiency of DCF decomposition & Reference \\
\hline \multirow[t]{3}{*}{ Photocatalytic, $\mathrm{TiO}_{2}$} & 15 & Complete in $1 \mathrm{~h}$ & [Calza et al. 2006] \\
\hline & $5-80$ & Complete $5 \mathrm{mg} / \mathrm{L}$ in $1 \mathrm{~h}$ & [Rizzo et al. 2009] \\
\hline & 10 & $61 \%$ in $1 \mathrm{~h}$ & [Achilleos et al. 2010] \\
\hline Photocatalytic with $\mathrm{H}_{2} \mathrm{O}_{2}$ & 296 & $90 \%$ in $90 \mathrm{~min}$ & [Vogna et al. 2004] \\
\hline $\begin{array}{l}\text { Photocataltytic with } \mathrm{TiO}_{2} \\
\quad \text { functionalized CNT and } \mathrm{H}_{2} \mathrm{O}_{2}\end{array}$ & 8.0 & Complete in $10 \mathrm{~min}$ & [Martinez et al. 2011] \\
\hline Solar radiation & 50 & $83 \%$ in 1 day & [Bartels et al. 2007] \\
\hline Solar radiation & 45.5 & $\begin{array}{l}70 \% \text { in } 30 \mathrm{~min} \text {; complete in } \\
160 \mathrm{~h}\end{array}$ & [Aguera et al. 2005] \\
\hline Solar radiation, $\mathrm{TiO}_{2}$ & 43 & Complete in $3 \mathrm{~h}$ & [Perez-Estrada et al. 2005a] \\
\hline Solar photo-Fenton & 55 & Complete in $100 \mathrm{~min}$ & [Perez-Estrada et al. 2005b] \\
\hline Photo-Fenton & 18 & Complete mineralization in $1 \mathrm{~h}$ & [Ravina et al. 2002] \\
\hline Pyrite catalyzed Fenton & 5.0 & Complete in $2 \mathrm{~min}$ & [Bae et al. 2013] \\
\hline Ozonation & 296 & Complete in $8 \mathrm{~min}$ & [Vogna et al. 2004] \\
\hline Ozonation & 40 & $90 \%$ in $40 \mathrm{~min}$ & [Naddeo et al. 2009] \\
\hline Ozonation, $\mathrm{H}_{2} \mathrm{O}_{2}$ & 0.002 & $97 \%$ in $10 \mathrm{~min}$ & [Zwiener et al. 2000] \\
\hline Photocatalytic ozonation & 30 & Complete in $3 \mathrm{~min}$ & [Aguinaco et al. 2012] \\
\hline Sonolysis & 80 & $55 \%$ in $1 \mathrm{~h}$ & [Naddeo et al. 2009] \\
\hline Sonolysis & 40 & $50 \%$ in $1 \mathrm{~h}$ & [Naddeo et al. 2010] \\
\hline Sonolysis & 15 & $26 \%$ in $1 \mathrm{~h}$ & [Nie et al. 2014] \\
\hline Sonolysis with $\mathrm{TiO}_{2}$ & 50 & $84 \%$ in $30 \mathrm{~min}$ & [Hartmann et al. 2008] \\
\hline Sonoelectrochemical & 0.05 & $90 \%$ in $5 \mathrm{~min}$ & [Finkbeiner e tal. 2015] \\
\hline Sonophotolysis & 10 & $96 \%$ in $2 \mathrm{~h}$ & [Michael et al. 2014] \\
\hline Catalytic oxidation, $\mathrm{H}_{2} \mathrm{O}_{2}$ & 20 & Complete in $30 \mathrm{~min}$ & [Hoffmann et al. 2007] \\
\hline Oxidation with $\mathrm{ClO}_{2}$ & 0.9 & $75 \%$ in $1 \mathrm{~min}$ & [Wang et al. 2015] \\
\hline Electro-oxidation & 30 & $72 \%$ mineralization in $4 \mathrm{~h}$ & [Zhao et al. 2009] \\
\hline Pulsed corona discharge & 50 & Complete in $15 \mathrm{~min}$ & [Dobrin et al. 2013] \\
\hline
\end{tabular}

some essential differences can be found in reported results [Vogna et al. 2004, Naddeo et al. 2009, Zwiener et al. 2000]. Some evident progress in this field was made in the recent few years by the application of such treatment methods as the photocatalytic treatment with $\mathrm{TiO}_{2}$ functionalized carbon nanotubes in the presence of $\mathrm{H}_{2} \mathrm{O}_{2}$ [Martinez et al. 2011], the pyrite catalyzed Fenton reaction [Bae et al. 2013], the photocatalytic ozonation [Aguinaco et al. 2012], the sonoelectrochemical treatment [Finkbeiner et al. 2015], or employing the pulsed corona discharge [Dobrin et al. 2013].

Recently, first papers on radiolytic decomposition of diclofenac were also published [Liu et al. 2011, Homolok et al. 2011, Kimura et al. 2012, Trojanowicz et al. 2012, Yu et al. 2013]. In studies carried out at initial concentration levels $20-50 \mathrm{mg} / \mathrm{L}$, it was showed that degradation of DCF by $\gamma-$ irradiation in aqueous solutions can result both from the radical reaction with hydroxyl radical ${ }^{\circ} \mathrm{OH}$ and hydrated electron $\mathrm{e}_{\mathrm{aq}}{ }^{-}$, which are produced from the radiolysis of water [Liu et al. 2011, Homolok et al. 2011, Yu et al. 2013]. It was also indicated that the yield of degradation is larger in acidic medium than neutral or alkaline [Liu et al. 2011]. The changes of Microtox ${ }^{\circledR}$ toxicity were also examined in terms of absorbed radiation dose [Homolok et al. 2011, Yu et al. 2013]. The rate constant for reaction of DCF with ${ }^{\circ} \mathrm{OH}$ was determined as 9.0 [Kimura et al. 2012] and $9.29 \times 10^{9} \mathrm{M}^{-1} \mathrm{~s}^{-1}$ [Yu et al. 2013]. Very recently, when this study was in progress also, the rate constant for the reaction with $e_{\text {aq }}^{-} 1.53 \times 10^{9} \mathrm{M}^{-1} \mathrm{~s}^{-1}$ was reported [Yu et al. 2013]. In our initial studies, we also demonstrated the oxidative and reductive pathways of radical degradation of DCF, although a more efficient degradation of DCF with ${ }^{\circ} \mathrm{OH}$ radicals was observed at low absorbed radiation doses, where no complete decomposition is obtained at the initial DCF concentration $50 \mathrm{mg} / \mathrm{L}$ [Trojanowicz et al. 2012]. For the identification of main products of DCF decomposition, the gas chromatography-mass spectrometry (GC/ MS) and high-performance liquid chromatography (HPLC) with UV detection were employed. 
The aim of this work was investigation of the yield of the radiolytic decomposition of DCF by means of gamma radiation, the determination of rate constants for radical reactions of DCF with products of water radiolysis, and also the monitoring of toxicity changes during radiolytic decomposition. For some comparison and more general picture of carried out processes, irradiated solutions contained also two other very commonly used pharmaceuticals - carbamazepine and ibuprofen, and also a very common industrial pollutant bisphenol A. For instance, the presence of carbamazepine was reported in $40 \%$ of large collection of waters intended for human consumption [Houeto et al. 2012], while commonly found ibuprofen in environmental waters may reach in wastewater the concentration level $373 \mu \mathrm{g} / \mathrm{L}$, and in effluent from wastewater treatment plants $48 \mu \mathrm{g} / \mathrm{L}$ [Santos et al. 2007]. Bisphenol A concentration in hazardous wastes may reach level $17 \mathrm{mg} / \mathrm{L}$, and in water samples, $12 \mu \mathrm{g} / \mathrm{L}$ [Suzuki et al. 2004]. The progress of radiolytic processes was monitored not only in model aqueous solutions, as it was reported in earlier works [Homolok et al. 2011, Yu et al. 2013], but also in real environmental samples at the concentration level similar to that reported in some earlier environmental studies. For this purpose, mostly HPLC with UV-Vis detection was used, whereas for detailed identification of products of DCF radiolytic decomposition, the LC/MS/MS method was employed. The rate constants for radical reactions with DCF pulse radiolysis was determined using pulse radiolysis method with spectrophotometric detection.

\section{Experimental}

\section{Chemicals}

All chemicals applied were of the highest purity grade available and were used as received (Sigma, Aldrich), except acetonitrile, methanol, and potassium dihydrogen orthophosphate purchased from J.T. Baker, Poland. All target compounds of this study, namely diclofenac (DCF) (2-(2-(2,6dichlorophenylamino) phenyl)acetic acid), ibuprofen (((RS)2-(4-methyl-propyl)phenyl)propanoic acid), carbamazepine (5H-dibenzo[b,f]azepine-5-carboxamide), and bisphenol A were purchased from Sigma Aldrich, Poland. Solutions of analytes were prepared in deionized Milli-Q water.

Samples of river water were collected in Warsaw from the river Vistula in location prior to the outlet from the municipal wastewater treatment plant, whereas hospital wastewater was obtained from the local hospital.

\section{Irradiation facility}

Within this study, aqueous solutions of investigated analytes or samples were $\gamma$-irradiated using ${ }^{60} \mathrm{Co}$ source gamma chamber with a dose rate of $4.8 \mathrm{kGy} / \mathrm{h}$. The samples were irradiated in closed $10-\mathrm{mL}$ conical glass flasks. The dosimetry was carried out with Fricke solution.

\section{Analytical procedures}

The reversed-phase HPLC determinations of DCF were carried out using Shimadzu LC-10 AT chromatograph with the diode array UV-Vis detector model SPD-M10A VP. The analytical column Phenomenex Luna C18 (2) $250 \times 4.6 \mathrm{~mm}$, $5 \mu \mathrm{m}$, and a guard column (Torrance, CA, USA) were used. The injected sample volume was $20 \mu \mathrm{L}$. In method A, with shorter total run time about $12 \mathrm{~min}$, as eluent, the mixture of $0.2 \mathrm{M}$ aqueous solution of formic acid and acetonitrile 40:60 at $\mathrm{pH} 4$ was used. In method $\mathrm{B}$, with total run about $60 \mathrm{~min}$, as eluent, the mixture of $0.6 \mathrm{mM}$ aqueous solution of $\mathrm{KH}_{2} \mathrm{PO}_{4}$, acetonitrile, and methanol in ratio 50:30:20 of pH 4 was used. In both methods, the UV detection was carried out at $220 \mathrm{~nm}$.

The solid-phase preconcentration of analytes was carried with Oasis HLB columns (Waters), which were conditioned by flushing with $3 \mathrm{~mL}$ methanol and $3 \mathrm{~mL}$ water at $5 \mathrm{~mL} / \mathrm{min}$, then $500-\mathrm{mL}$ sample was loaded. In the next steps, the bed was rinsed with $1 \mathrm{~mL} 5 \%$ methanol, and analytes were eluted with $3 \mathrm{~mL}$ methanol.

The ion-chromatographic determinations of chloride were performed using chromatograph Dionex model 2000i/sp, equipped with an ASRS I electrochemical anion selfregenerating suppressor, conductivity detector, AG9HC guard column, and AS9HC analytical anion exchange column from Dionex. Mobile phase of the system was sodium carbonate and sodium bicarbonate with a flow rate of $1 \mathrm{~mL} / \mathrm{min}$.

LC/MS measurements were carried out using LC-Ion trap-time-of-flight MS system from Shimadzu. Chromatography was carried out using gradient elution with the following eluents A: $0.1 \%$ formic acid and B: acetonitrile, $0.1 \%$ formic acid. Flow rate: $0.5 \mathrm{~mL} / \mathrm{min}$. Gradient: $0-3 \mathrm{~min}$ : $30 \% \mathrm{~B}$, then from 3 to $10 \mathrm{~min}, 30-40 \%$, then $10-40 \mathrm{~min}$, from 40 to $65 \%$, then $40-45 \mathrm{~min}$, from 65 to $100 \%, 45-46$, $100 \%$, then $46-47$, from 100 to $30 \%$ (equilibration) and from 47-55 min, $30 \%$ (initial mobile phase composition for equilibration).

The MS conditions were as follows: full-scan acquisition with polarity switching; mass range $\mathrm{m} / \mathrm{z} 150-1000$; ion trap accumulation time $50 \mathrm{~ms}$

\section{Pulse radiolysis}

The pulse radiolysis was carried out in the nanosecond pulse radiolysis facility based on the electron accelerator LAE 10 installed at the Institute of Nuclear Chemistry and Technology in Warsaw [Bobrowski 2005]. It allows to carry out pulse 
radiolysis experiments with pulse duration (4-10 ns, $100 \mathrm{~ns})$, electron energy $10 \mathrm{MeV}$, and beam power $0.2 \mathrm{~kW}$.

\section{Toxicity measurements}

For the monitoring of toxicity changes of the irradiated solutions, two commercial- and one laboratory-made tests were employed. The Microtox ${ }^{\circledR}$ bacterial acute toxicity test based on measuring bioluminescence of Vibrio fischeri using M500Toxicity Analyzer from Azur Environment (Wokingham, UK). The Thamnotoxkit FTM microbiotest with crustacean Thamnocephalus platyurus was obtained from MicroBioTests Inc. (Mariakerke, Belgium). Spirotox acute toxicity test, based on the use of a very large ciliated protozoan Spirostomum ambiguum, was developed in the Department of Environmental Health Sciences, Medical University of Warsaw, where over four order of magnitude toxicity changes can be monitored for different groups of chemical compounds [Nałęcz-Jawecki et al. 1999].

\section{Results and discussion}

\section{Optimization of analytical procedures employed}

Due to a very wide use of diclofenac, hundreds of research papers were published on the development of various analytical methods for its determination in pharmaceutical preparations and physiological fluids, and for the monitoring of its residues in environmental samples. They include spectrophotometric, electrochemical, and especially commonly used the high-performance separation methods. GC/MS methods require a preliminary derivatization of polar DCF, e.g., [Farre et al. 2007, Shin et al. 2012]. In recent years, the most commonly used method is HPLC with different detections, mainly UV and mass spectrometry detection, which were also employed in this study. The HPLC-UV methods were employed in this work for the investigation of the decomposition yield of examined species in different conditions, whereas the LC/MS/MS for the identification of products of radiolytic decomposition of DCF.

A quick HPLC-UV method A was employed for the basic measurements in pure aqueous solutions of irradiated analytes, where a satisfactory baseline separation was obtained for all analytes in $12 \mathrm{~min}$ (Fig. 1a), with sufficient values of the limit of detection (LOD) (see Table 2) for the monitoring of decomposition of analytes at the initial concentration level of several milligrams per liter. This method, however, cannot be employed directly for the monitoring of radiolytic decomposition of analytes in natural waters of wastes due to a large signal of other constituents of natural samples, which are eluted with short retention times and they overlap signals for carbamazepine and bisphenol A, which were additionally monitored in some experiments besides DCF. The developed HPLC-UV method B exhibits also the baseline resolution of the examined solutes, allowing a significant reduction of the magnitude of overlapping signals from natural samples; however, it takes much longer time when isocratic elution is employed. For the routine monitoring of such a processes, a disadvantageous long running time can be substantially shortened by a careful optimization of the gradient elution.

For the application of those methods in micrograms per liter or sub-micrograms per liter concentration range, the additional step of the analyte preconcentration using a solidphase extraction was also employed. It was carried out using commercial columns loaded with $60 \mathrm{mg}$ Oasis HLB resin (Waters). In optimized conditions, the analytes were preconcentrated 250 times, with the use of $500-\mathrm{mL}$ initial sample volume with $\mathrm{pH}$ adjusted to 8.0 , and eluted with a satisfactory recovery using 2-mL methanol. The limits of detection (LOD) values for DCF, and also for three other analytes which were examined are listed in Table 2 . They were considered as satisfactory for the investigation of the yield of radiolytic DCF decomposition using $\gamma$-irradiation in low micrograms per liter level.

\section{Optimization of the irradiation conditions}

In dilute aqueous solutions $(<0.1 \mathrm{M})$ the decomposition of organic pollutants by ionizing radiation is initiated by the primary products of water radiolysis ${ }^{\circ} \mathrm{OH}, e_{\mathrm{aq}}{ }^{-}$, and ${ }^{\circ} \mathrm{H}$, formed according to the following reaction [Buxton et al. 1988]:

$$
\begin{gathered}
\mathrm{H}_{2} \mathrm{O} \stackrel{\text { radiolysis }}{\longrightarrow}[0.28]^{\circ} \mathrm{OH}+[0.06]^{\circ} \mathrm{H}+[0.27] e_{\mathrm{aq}}{ }^{-} \\
+[0.05] \mathrm{H}_{2}+[0.07] \mathrm{H}_{2} \mathrm{O}_{2}+[0.27] \mathrm{H}^{+}
\end{gathered}
$$

The numbers shown in brackets are $G$ values (reported as radiolytic yield or radio-chemical yield) for each species $\left(\mu \mathrm{M} \mathrm{J}^{-1}\right)$ of adsorbed energy. Depending on employed chemical conditions during irradiation, and especially on the presence of purposely selected scavengers, one can adjust the concentration of selected predominating reactive species. For instance, in $\mathrm{N}_{2} \mathrm{O}$-saturated solutions, as result of reactions (2) and (3):

$e_{\mathrm{aq}}{ }^{-}+\mathrm{N}_{2} \mathrm{O}+\mathrm{H}_{2} \mathrm{O} \rightarrow \mathrm{N}_{2}+\mathrm{OH}^{-}+{ }^{\cdot} \mathrm{OH}$
$\cdot \mathrm{H}+\mathrm{N}_{2} \mathrm{O} \rightarrow \cdot \mathrm{OH}+\mathrm{N}_{2}$

with the reaction rate constant values $9.1 \times 10^{9}$ and $2.1 \times$ $10^{6} \mathrm{M}^{-1} \mathrm{~s}^{-1}$, respectively [Buxton et al. 1988], an increase of the concentration of hydroxyl radicals can be obtained, providing a strongly oxidizing conditions. It was reported that the total hydroxyl radical yield in $\mathrm{N}_{2} \mathrm{O}$-saturated conditions is $0.59 \mu \mathrm{M} \mathrm{J}^{-1}$ [Buxton et al. 1995]. 
Fig. 1 HPLC chromatograms recorded for standard mixtures of the determined analytes using two developed methods with isocratic elution. a Eluent composition: $40 \% 0.2 \mathrm{M}$ formic acid, $60 \%$ acetonitrile, $\mathrm{pH} 4.0$; injection $4 \mathrm{mg} / \mathrm{L}$ each analyte (method A). b Eluent composition: $50 \%$ $0.6 \mathrm{mM} \mathrm{KH}_{2} \mathrm{PO}_{4}, 30 \%$ acetonitrile, $20 \%$ methanol, $\mathrm{pH}$ 4.0; injection $2 \mathrm{mg} / \mathrm{L}$ each analyte (method B). In both cases: flow rate $1 \mathrm{~mL} / \mathrm{min}$, detection $\mathrm{UV}$ at $220 \mathrm{~nm}$

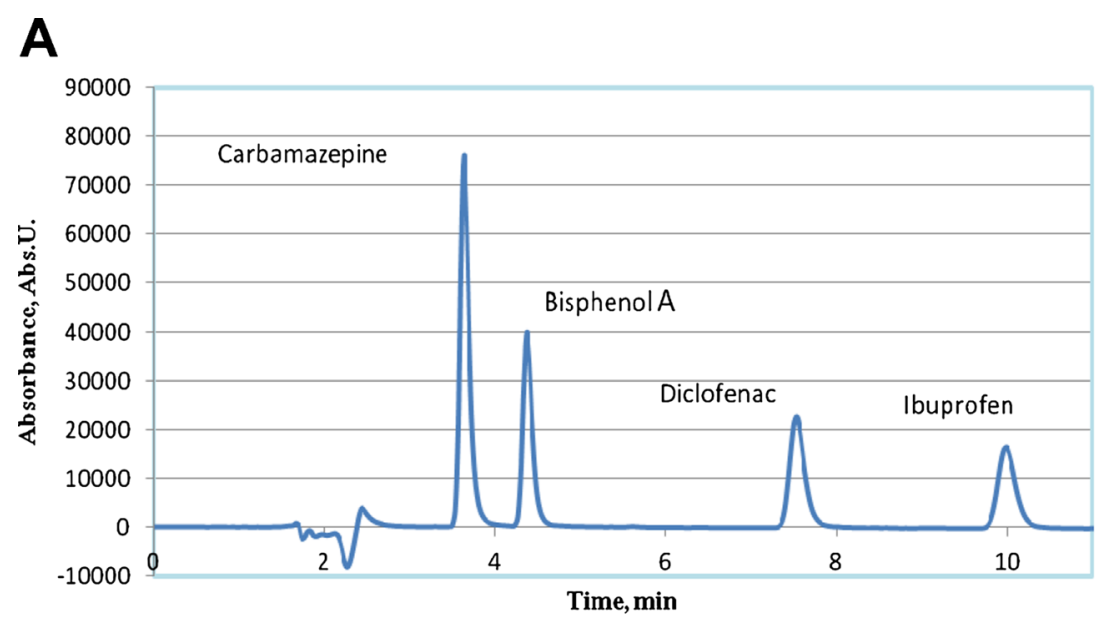

B

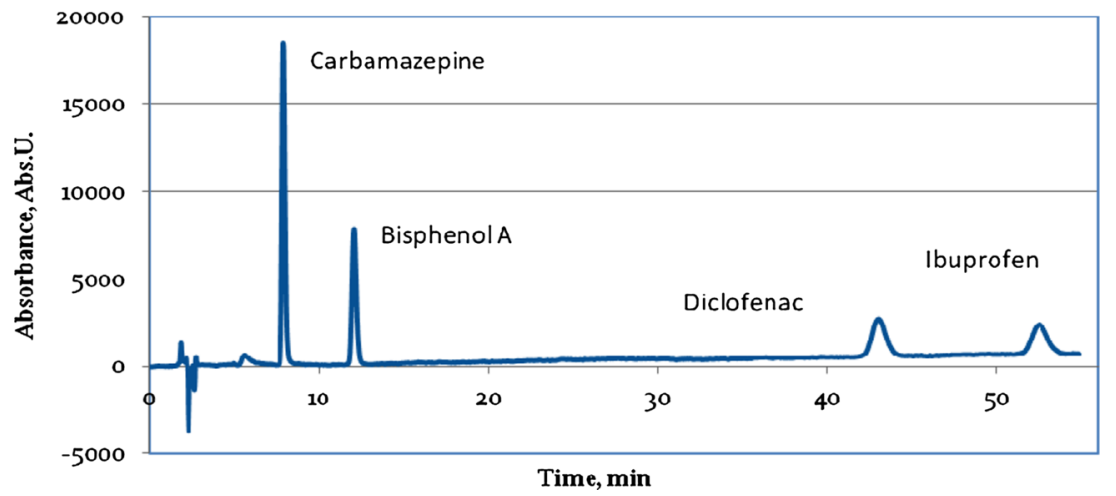

Similarly, the absence of reductive products of water radiolysis is observed when irradiated solutions are aerated, due to a fast reactions of those species with dissolved molecular oxygen $(4,5)$ :

$e_{\mathrm{aq}^{-}}+\mathrm{O}_{2} \rightarrow \mathrm{O}_{2}{ }^{--}$

$\cdot \mathrm{H}+\mathrm{O}_{2} \rightarrow \mathrm{HO}_{2}{ }^{\cdot}$

With the rate constant values $1.2 \times 10^{10}$ and $1.9 \times$ $10^{10} \mathrm{M}^{-1} \mathrm{~s}^{-1}$, respectively [Buxton et al. 1988].

In case of the irradiation of deaerated solutions the addition of $t$-butanol to solution allows the removal of ${ }^{\circ} \mathrm{OH}$ and ${ }^{\circ} \mathrm{H}$ radicals from the solution as result of reactions (6) and (7):

$\cdot \mathrm{OH}+\left(\mathrm{CH}_{3}\right)_{3} \mathrm{COH} \rightarrow{ }^{\cdot} \mathrm{CH}_{2} \mathrm{C}\left(\mathrm{CH}_{3}\right)_{2} \mathrm{OH}+\mathrm{H}_{2} \mathrm{O}$

$\cdot \mathrm{H}+\left(\mathrm{CH}_{3}\right)_{3} \mathrm{COH} \rightarrow{ }^{\circ} \mathrm{CH}_{2} \mathrm{C}\left(\mathrm{CH}_{3}\right)_{2} \mathrm{OH}+\mathrm{H}_{2}$ with rate constant values $6.6 \times 10^{8}$ and $1.7 \times 10^{5} \mathrm{M}^{-1} \mathrm{~s}^{-1}$, respectively [Buxton et al. 1988]. This allows utilizing the hydrated electrons, only, as a reactive species. In the same conditions, but at $\mathrm{pH} 2.0$ or below, a fast reaction (8):

$e_{\mathrm{aq}}{ }^{-}+\mathrm{H}^{+} \rightarrow{ }^{\cdot} \mathrm{H}$

takes place with the rate constant $2.3 \times 10^{10} \mathrm{M}^{-1} \mathrm{~s}^{-1}$ [Getoff 1996], providing conditions for the reaction with hydrogen radicals only.

Our preliminary studies on the irradiation of DCF were focused on the experimental determination of the yield of radiolytic decomposition in various conditions of irradiation, where different products of water radiolysis predominate [Trojanowicz et al. 2012] and the yield of decomposition was different in oxidative and reductive conditions due to

Table 2 The limit of detection (LOD) values $(\mu \mathrm{g} / \mathrm{L})$ obtained in the employed HPLC-UV methods using $20-\mu \mathrm{L}$ injection volume

\begin{tabular}{lllll}
\hline Method & Diclofenac & Carbamazepine & Ibuprofen & Bisphenol A \\
\hline Method A & 26.3 & 7.90 & 35.0 & 15.1 \\
Method A with 250-fold enrichment & 0.11 & 0.03 & 0.14 & 0.06 \\
Method B with 250-fold enrichment & 2.30 & 0.30 & 2.96 & 0.66 \\
\hline
\end{tabular}


different reactivity of predominating species under particular conditions. For the examined level of the initial DCF concentration $50 \mathrm{mg} / \mathrm{L}$, it was showed that the DCF decomposition in aerated aqueous solution requires dose $4.0 \mathrm{kGy}$, while in the process carried out with the scavenging of the solvated electron by saturation of the irradiated solution with $\mathrm{N}_{2} \mathrm{O}$, leading to substantial increase of hydroxyl radicals according to Eqs. (2) and (3), the required dose drops down to $1 \mathrm{kGy}$. The deaeration of irradiated solution by saturation with argon and irradiation in the presence of tert-butanol decreases yield of DCF irradiation only in the range of doses from 0.5 to $3 \mathrm{kGy}$, whereas above $3 \mathrm{kGy}$, it has no effect. This shows evidently, that the radiolytic degradation is more efficient in the oxidative conditions, and this is also confirmed by the calculated $G$ values and evaluated rate constant values for reactions of DCF with hydroxyl radicals and hydrated electron, which are reported below.

The yield of radiolytic decomposition of organic pollutants in some cases may be affected by the presence of radical scavengers present in natural environmental samples. Most commonly, their effect results in lowering the yield of radiolytic decomposition of target pollutants; however, in some cases, also positive effects have been reported. In this study, which is focused on application of this method to natural waters and wastes, the optimized HPLC method A was employed to examine the effect of the presence of ${ }^{\circ} \mathrm{OH}$ radical scavengers such as nitrate, carbonate, or humic acid on decomposition of DCF. As it is shown by data in Fig. 2, the yield of the DCF degradation at $50 \mathrm{mg} / \mathrm{L}$ level is not affected by the presence of those naturally occurring scavengers. Some effects, however, were observed for the yield of chloride released from DCF and its degradation products in different conditions of irradiation, where for instance, the presence of $50 \mathrm{mg} / \mathrm{L}$ carbonate or nitrate inhibits a complete dechlorination of organic products of the DCF decomposition. In contrary, the presence of the humic substances gives opposite effect, as it was also reported earlier for radiolytic decomposition of pesticide atrazine [Basfar et al. 2009].

The effectiveness of the radiolytic decomposition of DCF in pure aqueous solutions in different conditions of gamma irradiation was already examined and reported in several works cited in "Introduction." It was showed that the most efficient decomposition occurs as result of reaction with hydroxyl radicals. In this study, the efficiency of decomposition was examined also in natural samples of a river water and hospital wastewater, which were spiked with $10 \mu \mathrm{g} / \mathrm{L} \mathrm{DCF}$, and also for comparison with three other common pollutants of natural waters, namely ibuprofen, carbamazepine, and bisphenol A. The irradiation was carried out in the oxidizing conditions in aerated samples, which are the simplest conditions for practical applications, which does not require any additional sample processing. At the same time, they are also favorable conditions from the point of view of a possible radical reactions. As it was already mentioned, in order to reduce the effect of matrix components, the HPLC measurements of irradiated solutions were carried out using method $\mathrm{B}$ with additional 250 times preconcentration with Oasis HLB column. As can be expected, and what is showed by chromatograms recorded at different absorbed doses (Fig. 3), the hospital effluent has a matrix exhibiting a larger content of constituents, which are retained on sorbent Oasis HLB, and they are then eluted in HPLC measurement with the retention time below $5 \mathrm{~min}$. Certainly, many of those components can react with products of water radiolysis in competitive radical reactions, leading to decrease of the decomposition yield of examined analytes.

As shown in Fig. 3b, the irradiation of the hospital effluent with added $10 \mu \mathrm{g} / \mathrm{L}$ of each analyte was investigated with the use of absorbed doses up to $0.5 \mathrm{kGy}$. One can see, that only in case of diclofenac and ibuprofen, it was sufficient as the complete decomposition was observed at $0.25 \mathrm{kGy}$. The comparison of the effect of matrix type on the yield of decomposition of examined compounds is illustrated by the signal changes in recorded chromatograms for river water and hospital effluent samples (Fig. 4). The obtained results indicate that especially the decomposition of carbamazepine and bisphenol A requires much larger irradiation doses in case of the hospital effluent, than in river water samples. In case of bisphenol A, the application of 100 Gy absorbed dose allows the decomposition of $95 \%$ in river water, while $70 \%$ only in hospital effluent. For carbamazepine, those yields were 90 and $37 \%$, respectively. As far as diclofenac is concerned, for initial level of $10 \mu \mathrm{g} / \mathrm{L}$ used in spiked samples, as complete decomposition in river water was obtained for $100 \mathrm{~Gy}$ absorbed dose, while in the hospital effluent - 250 Gy absorbed dose was needed.

Results of those experiments, performed close to a real content of residues, which can exist in the polluted environmental samples firmly show a very essential impact of the matrix composition on the yield of decomposition of pharmaceutical. The observed complete decomposition at absorbed dose level about $1 \mathrm{kGy}$ indicates, that radiolytic AOP process may be a competitive method for the decomposition of pharmaceutical residues from waters and wastes compared to methods routinely used nowadays.

\section{Examination of toxicity changes}

A very important supplement to analytical investigation of the efficiency of radiolytic decomposition of organic pollutants for environmental protection is the monitoring of toxicity changes in the irradiated solutions. This allows the determination of authentic environmental impact of applied processes with the use of different test organisms. An increased toxicity of DCF solutions was reported after photocatalytic treatment in the presence of $\mathrm{TiO}_{2}$ [Achilleos et al. 2010], as well as after (sono)photocatalytic processing 
Fig. 2 Chromatographic examination of the effect of selected scavengers of radicals on the a yield of DCF radiolytic decomposition and $\mathbf{b}$ on release of chloride in function of different absorbed dose. a Examined using the HPLC-UV method A. b Examined using the suppressed ion-chromatography with the conductivity detection. Gammairradiated aqueous solution of DCF $50 \mathrm{mg} / \mathrm{L}$ were saturated with air

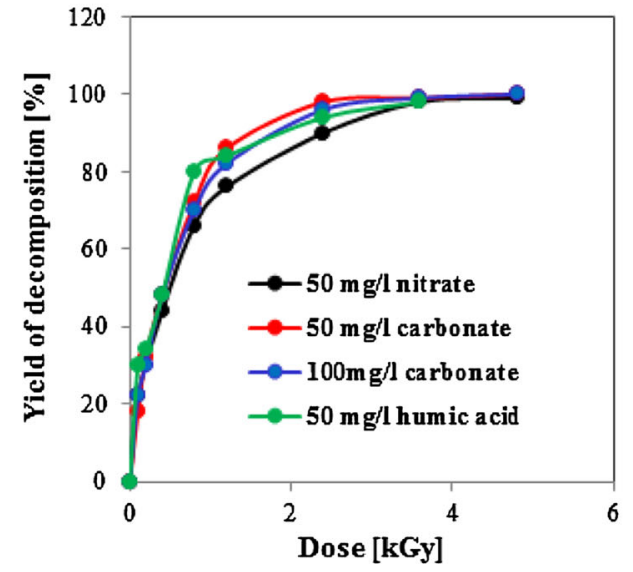

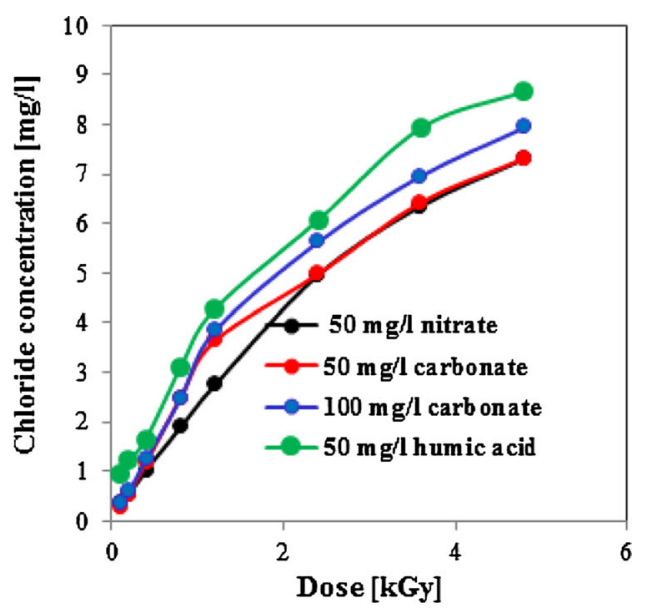

[Michael et al. 2014], which was attributed to the formation of a variety of chloroderivatives of high toxicity.

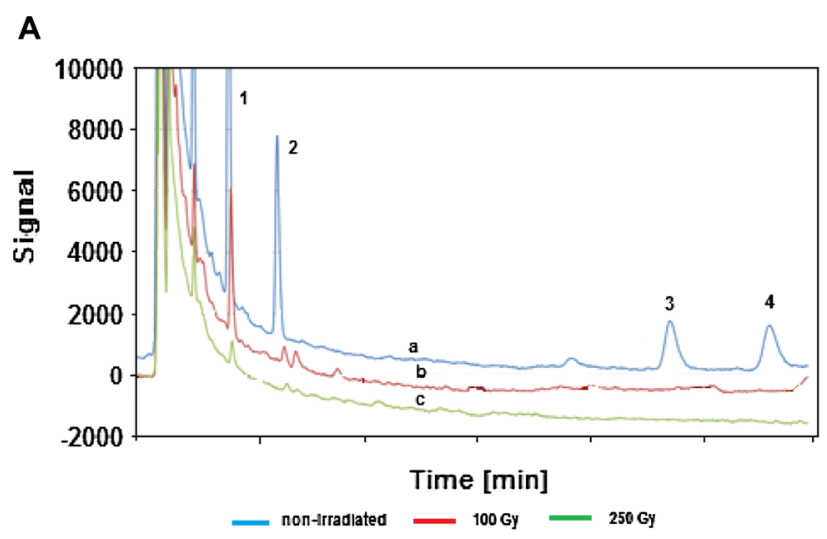

B

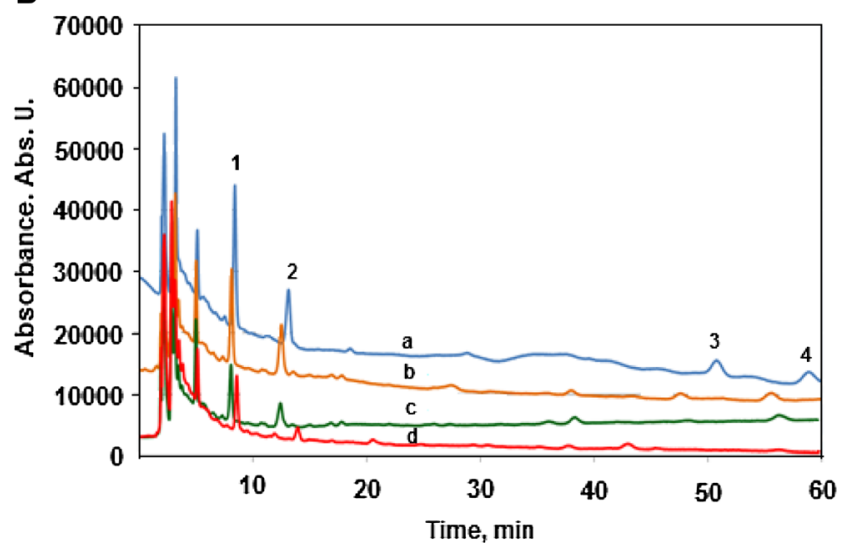

Fig. 3 HPLC chromatograms obtained with method B and 250-fold SPE preconcentration for the aerated natural samples $\gamma$-irradiated with different doses. a Chromatograms of Vistula River water spiked with $10 \mu \mathrm{g} / \mathrm{L}$ concentration of each analyte, obtained for sample prior to the irradiation (a), after $\gamma$-irradiation with dose $100 \mathrm{~Gy}(b)$, and $250 \mathrm{~Gy}(c)$. b Chromatograms recorded in the same conditions for sample of wastewater from hospital spiked with $10 \mu \mathrm{g} / \mathrm{L}$ each analyte prior to $\gamma$ irradiation (a), after irradiation with $100(b), 250(c)$, and $500(d)$ Gy dose. In both chromatograms: 1-carbamazepine, 2-bisphenol A, 3-DCF, 4ibuprofen
The toxicity measurements in this work were carried out for pure aqueous solutions of diclofenac irradiated with different absorbed doses. Up to now, for this purpose, the Microtox test was used, only [Homolok et al. 2011, Yu et al. 2013], which is based on the use of the bioluminescent marine bacterium $V$. fischeri as the test organism. In order to get a wider scope of toxic properties of diclofenac and products of its radiolytic

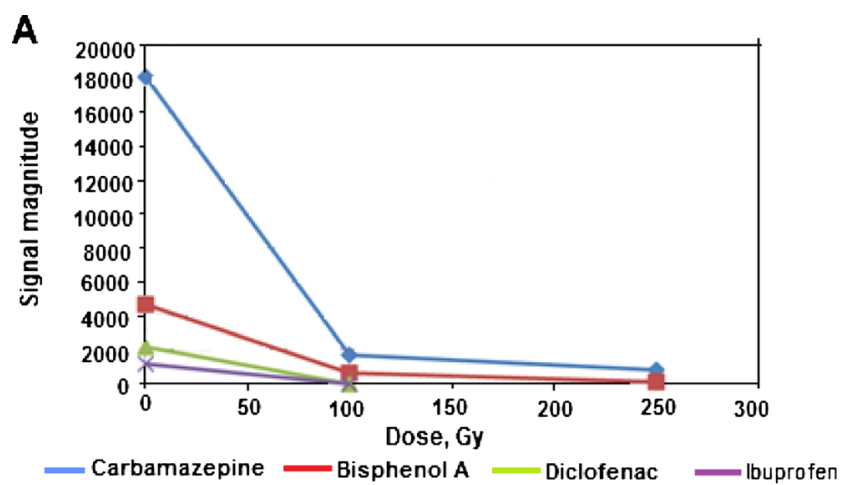

\section{B}

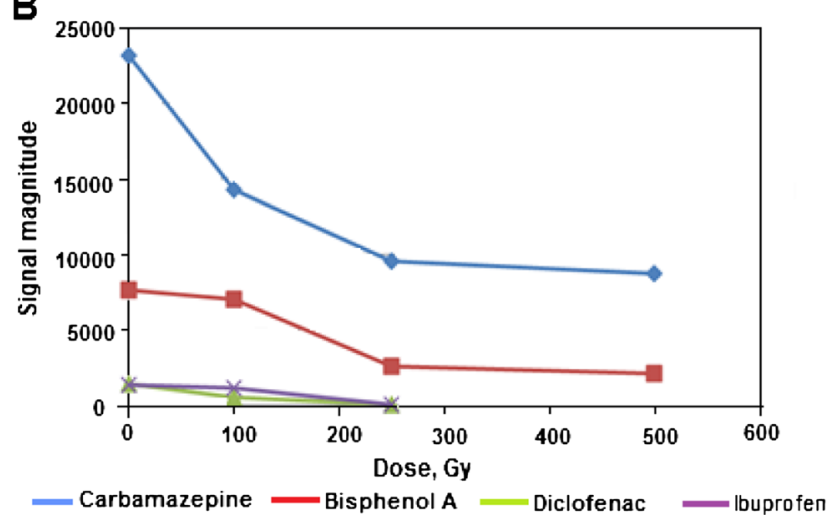

Fig. 4 Comparison of the yield of $\gamma$-irradiation of investigated compounds in function of the absorbed doses, expressed by the signal magnitude for each analyte recorded in HPLC-UV measurements (method B) for samples spiked with $10 \mu \mathrm{g} / \mathrm{L}$ concentration each. a River water sample from Vistula. b Effluent from hospital 
decomposition, besides the Microtox, two other tests were also employed, which are widely used in environmental toxicity studies. Spirotox is a test undertaken with a very large ciliated protozoan $S$. ambiguum, while Thamnotoxkit is a bioassay using larvae of the freshwater anostracan crustacean $T$. platyurus hatched from cysts. The toxicity studies were conducted for $50 \mathrm{mg} /$ L DCF solutions irradiated in aerated solution with doses up to $5 \mathrm{kGy}$. With all employed tests, a certain increase of toxicity was observed for the applied doses in the range $0.5-0.8 \mathrm{kGy}$, where as it was shown earlier that about 50-60\% of DCF is decomposed [Trojanowicz et al. 2012]. This indicates a larger toxicity of formed transient products from decomposed DCF at low level of absorbed doses of radiation. As it was shown earlier, this effect quite often occurs when synthetic chemicals degrade in the environment [Boxal et al. 2004], and was also observed widely in numerous AOP processes reported in the literature as well, including photocatalytic DCF decomposition mentioned above [Achilleos et al. 2010; Michael et al. 2014]. At $3.5 \mathrm{kGy}$ dose, where the complete decomposition of DCF is observed, $33 \%$ decrease of Microtox toxicity was observed. Further decrease of toxicity of irradiated solutions can be expected at higher values of the absorbed dose, when the decomposition of produced chlorinated products are mineralized. On the other hand, practically no changes of toxicity was found in comparison to initial values prior to irradiation with two other employed tests (Fig. 5). This means in practice rather low toxicity of DCF for organisms employed in those two tests, and also an expected diversified environmental impact of DCF residues in waters and wastes on different organisms.

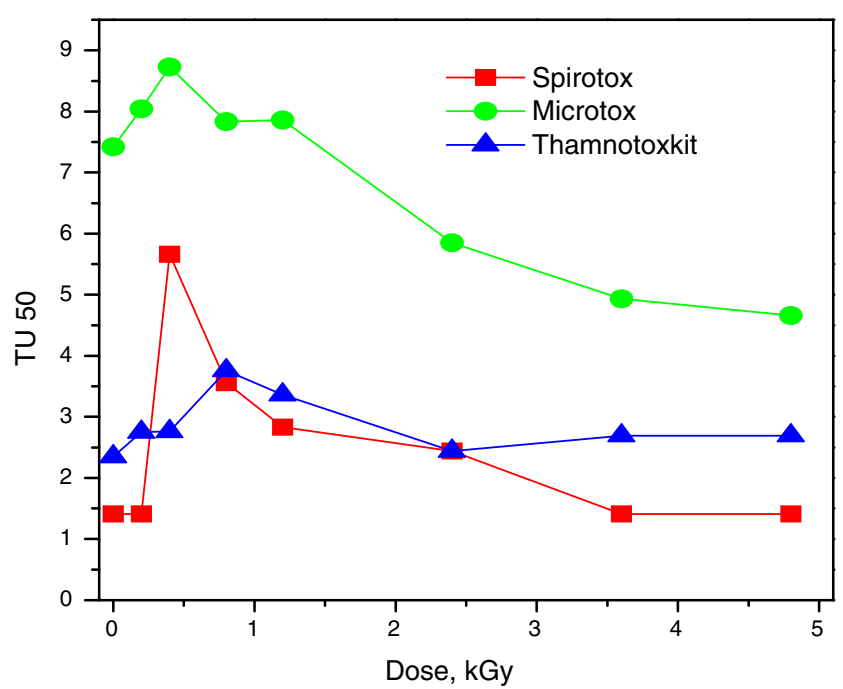

Fig. 5 Toxicity changes observed with different toxicity tests at different absorbed doses for $\gamma$-irradiation of $50 \mathrm{mg} / \mathrm{L}$ aerated solution of diclofenac

\section{Determination of decomposition products}

In our preliminary investigation of products of the diclofenac radiolysis using the GC/MS method, only four main products were identified. Also, in earlier studies by other authors on radiolytic decomposition of DCF, only a few products of reactions of DCF with hydroxyl radicals and solvated electrons were identified [Liu et al. 2011, Homolok et al. 2011], while many more where detected, when LC/MS was employed, e.g., to the study of the decomposition of DCF by solar-driven photocatalysis [Aguera et al. 2005].

In these studies, using the HPLC analysis with mass spectrometry detection in the system with ion trap-time-of-flight analyzer (LC-IT-TOF MS), a much larger number of transient products were identified. The reported data concern $\gamma$ irradiation of aerated DCF solution at particular absorbed dose. As shown by the example total ion chromatograms, which were recorded with use of both modes of electrospray ionization for $50 \mathrm{mg} / \mathrm{L}$ diclofenac solution irradiated with $3.6 \mathrm{kGy}$ dose (where about $95 \%$ decomposition of diclofenac occurs) ten different products of diclofenac radiolysis were detected at different concentration level (Fig. 6). Their partial identification is given by data listed in Table 3 (together with conditions of chromatographic separation and MS detection). This is the most detailed attempt reported so far compared to earlier approaches [Liu et al. 2011, Homolok et al. 2011, Kimura et al. 2012, Yu et al. 2013] to identify products of diclofenac radiolysis, and to illustrate the occurring processes. Based on the obtained LC/MS data, the structure of numerous products was elucidated and they are summarized schematically in Fig. 7. The identified products allow to conclude the location of breaking the bonds in diclofenac structure (red bars in Fig. 7A) and attachment of - $\mathrm{OH}$ groups in transient products showed by blue letters. Then, in Fig. 7B, modifications of phenyl acetic acid part of DCF molecule observed in identified products are showed. Similarly, in Fig. $7 \mathrm{C}$ the changes of amino group linking phenyl groups detected among the products of DCF radiolysis are showed. Because the detailed investigation of products was carried out for one particular example of DCF solution and one adsorbed dose only, the pathway of decomposition similar to reported for other degradation processes, e.g., [Aguera et al. 2005] cannot be suggested

\section{Pulse radiolysis study}

As it was already mentioned above, in dilute aqueous solutions (below $0.1 \mathrm{M}$ ) radiolytic reactions of dissolved compounds involve radicals formed from radiolysis of water namely hydroxyl radical $(\mathrm{OH})$, and hydrated electron $\left(e^{-}{ }_{\text {aq }}\right)$ under the conditions in which these species predominate. In order to investigate the kinetics of ${ }^{\circ} \mathrm{OH}$ reaction with diclofenac, the aqueous solution at $\mathrm{pH} 5.6$ was saturated with 


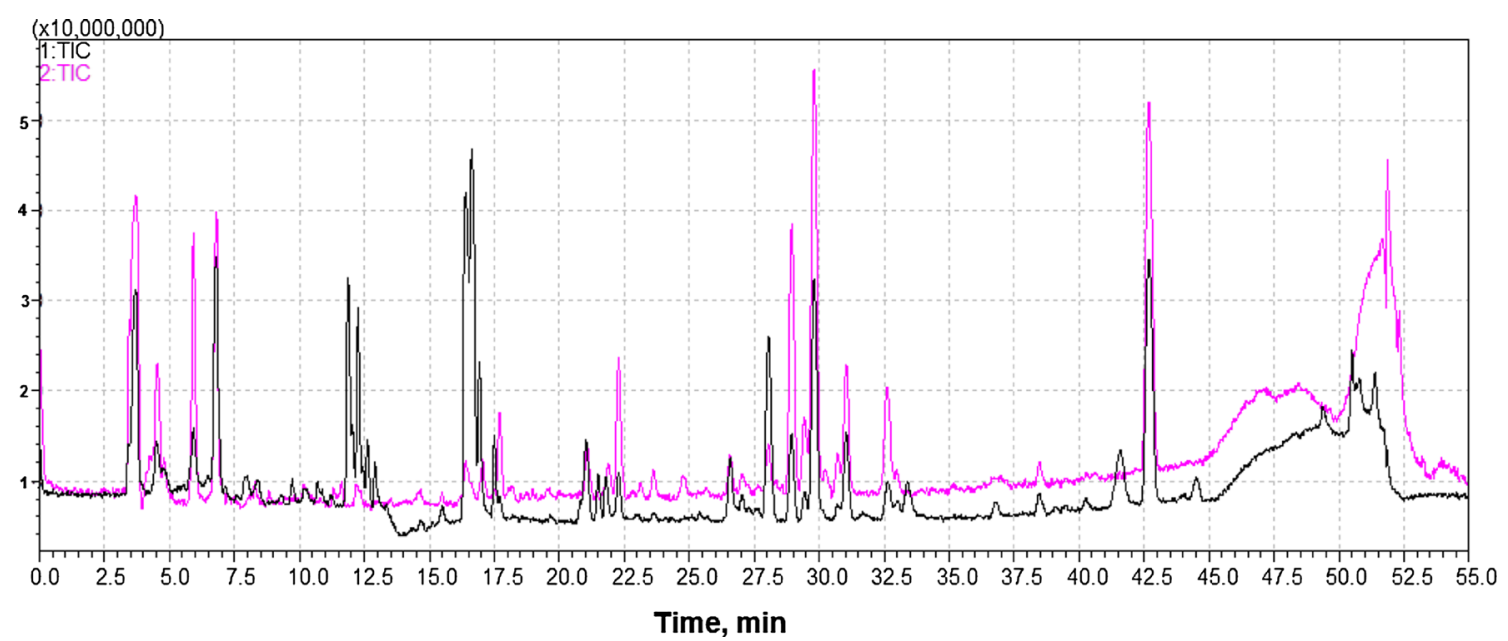

Fig. 6 Total ion current chromatograms recorded in the LC-IT-TOF MS system with electro-spray ionization in negative (1) and positive (2) mode for aqueous aerated solution $50 \mathrm{mg} / \mathrm{L} \mathrm{DCF} \gamma$-irradiated with $3.6 \mathrm{kGy}$ dose

$\mathrm{N}_{2} \mathrm{O}$, which reacts with solvated electron and hydrogen atom according to reactions (2) and (3). The absorption spectra recorded during the oxidation of diclofenac by ${ }^{\circ} \mathrm{OH}$ radical show three absorption bands with different intensity. The most intensive one is located at $\lambda_{\max }=370 \mathrm{~nm}$, and it grows up within $<0.8 \mu$ s time domain (Fig. 8 , curve B), with rate $k=(1.30 \pm 0.06) \times 10^{7} \mathrm{~s}^{-1}$, and decay with rate $k=(6.4 \pm 0.5) \times$ $10^{4} \mathrm{~s}^{-1}$. The second absorption band is located at shorter wavelength, and also is build up within microsecond time domain. The location of the second band is changing with the time, it starts at $335 \mathrm{~nm}$ (Fig. 8, curve A), after $0.8 \mu \mathrm{s}$, it moves to $325 \mathrm{~nm}$ (Fig. 8, curve B), and after $6 \mu$ s, is seen as a shoulder of the absorption band located at wavelength below $320 \mathrm{~nm}$ (start of measurement). This observation clearly indicates that at this region, more than one species respond for absorption, so its interpretation is ambiguous. The absorption spectra recorded $0.8 \mu \mathrm{s}$ after the electron pulse indicates additional shoulder-shape absorption (Fig. 8, curve B), and with elapsed time, it revels the absorption band at $430 \mathrm{~nm}$ (Fig. 8, curves $\mathrm{C}$ and $\mathrm{D}$ ).

The absorption spectrum recorded after end of $\mathrm{OH}$-radical reaction with diclofenac (Fig. 8, curve B) can be attributed to primary product(s) of oxidation diclofenac by ${ }^{\circ} \mathrm{OH}$ radicals. Probably it is adduct(s) of ${ }^{\circ} \mathrm{OH}$ to aromatic rings of diclofenac according to the following scheme:

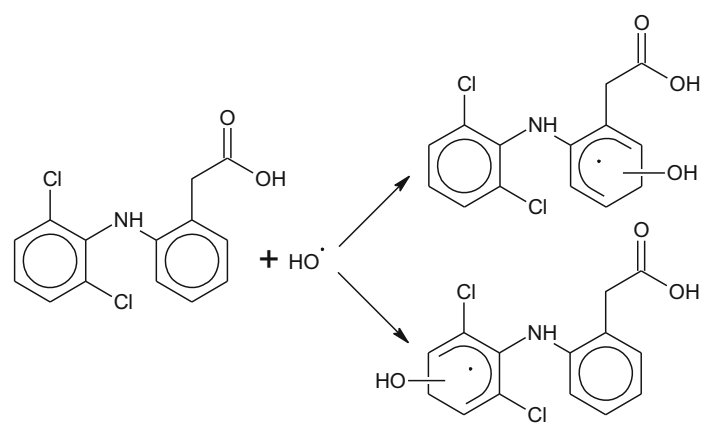

The overall rate constant of ${ }^{\circ} \mathrm{OH}$ radicals reaction with diclofenac deducted from the Stern-Volmer plot of absorption build-up at $\lambda_{\max }=370 \mathrm{~nm}$ is equal $k=(1.24 \pm$ $0.02) \times 10^{10} \mathrm{M}^{-1} \mathrm{~s}^{-1}$, (see inset in Fig. 8). This value is almost $40 \%$ larger than reported earlier [Kimura et al. 2012, Yu et al. 2013], which was evaluated by the competition reaction method with phenol as the reference compound. In a longer time scale, we observed the decay of absorption band with maximum $370 \mathrm{~nm}$, associated with the decay or transformations of primary products. The absorption of transient products of diclofenac oxidation recorded $0.5 \mathrm{~ms}$ after electron pulse (Fig. 8, curve D) reveals the absorption at $430 \mathrm{~nm}$ and a shoulder at a shorter wavelengths.

Investigation of diclofenac reaction with the solvated electron $e^{-}$aq has been performed in Ar-saturated aqueous solution. The $0.5 \mathrm{M}$ tertiary butyl alcohol $(t-\mathrm{BuOH})$ was added to scavenge the ${ }^{\circ} \mathrm{OH}$ radical and hydrogen atom according to reactions (6) and (7). Almost three orders of magnitude excess of $t-\mathrm{BuOH}$ concentration comparing to DCF concentration is used in order to complete scavenge the mentioned above hydroxyl and hydrogen radicals. The absorption spectrum recorded 120 ns after the electron pulse (Fig. 9, curve A) exhibits the intensive absorption with maximum over $700 \mathrm{~nm}$, assigned in the literature to hydrated electron [Boxal et al. 1976]. The spectrum recorded $1.6 \mu \mathrm{s}$ after pulse (after decay of the hydrated electron see Fig. 9, curve B) exhibits absorption between 450 and $320 \mathrm{~nm}$ with no distinctive maximum. The kinetics of growth at $330 \mathrm{~nm}$ and decay at $700 \mathrm{~nm}$ are complementary (data not shown). We can attribute this absorption to the product of reaction $e^{-}$aq with diclofenac: diclofenac $+e^{-}{ }_{\text {aq }}=>$ [diclofenac ${ }^{*}$. The overall rate constant of $e_{\text {aq }}^{-}$with diclofenac deducted from the SternVolmer plot of absorption decay at $700 \mathrm{~nm}$ is equal 
Table 3 The main products of radiolytic decomposition of diclofenac detected by LC-IT-TOF MS in $50 \mathrm{mg} / \mathrm{L}$ aqueous solution of DCF irradiated with $3.6 \mathrm{kGy}$ dose

\begin{tabular}{|c|c|c|c|c|c|c|c|}
\hline Compound & $\mathrm{RT}(\min )$ & $\begin{array}{l}\text { Experimental } \\
\mathrm{m} / \mathrm{z}\left([\mathrm{M}+\mathrm{H}]^{+}\right)\end{array}$ & $\begin{array}{l}\text { Assigned elemental } \\
\text { Composition }[\mathrm{M}]\end{array}$ & DBE & Error $(\mathrm{ppm})^{*}$ & In-source CID fragments & Comments \\
\hline Diclofenac (DCF) & 42.70 & 296.0234 & $\mathrm{C}_{14} \mathrm{H}_{11} \mathrm{NO}_{2} \mathrm{Cl}_{2}$ & 9 & 1.9 & $278 ; 214 \ldots$ & \\
\hline DCF-TP1 & 44.50 & 250.0184 & $\mathrm{C}_{13} \mathrm{H}_{9} \mathrm{NCl}_{2}$ & 9 & 0.7 & $\begin{array}{l}214 / 216 \\
215 / 217\end{array}$ & $\begin{array}{l}\text { Neutral loss of formic } \\
\text { acid (more apolar TP) }\end{array}$ \\
\hline DCF-TP 2 & 44.00 & 248.0458 & $\mathrm{C}_{13} \mathrm{H}_{10} \mathrm{NOCl}$ & 9 & 6.0 & & \\
\hline DCF-TP 3 & 43.87 & 230.0333 & $\mathrm{C}_{13} \mathrm{H}_{8} \mathrm{NOCl}$ & 10 & 14.9 & & Low int. \\
\hline DCF-TP 4 & 41.58 & 214.0394 & $\mathrm{C}_{13} \mathrm{H}_{8} \mathrm{NCl}$ & 10 & 11.3 & & \\
\hline DCF-TP 5 & 41.43 & 278.0126 & $\mathrm{C}_{14} \mathrm{H}_{9} \mathrm{NOCl}_{2}$ & 10 & 2.8 & & \\
\hline DCF-TP 6 & 40.25 & 262.0577 & $\mathrm{C}_{14} \mathrm{H}_{9} \mathrm{NOCl}$ & 9 & 20 & & Dechlorination \\
\hline DCF-TP 7 & 40.22 & 254.0066 & $\mathrm{C}_{12} \mathrm{H}_{9} \mathrm{NOCl}$ & 8 & 7.9 & & \\
\hline DCF-TP 8 & 37.11 & 244.0464 & $\mathrm{C}_{14} \mathrm{H}_{10} \mathrm{NOCl}$ & 10 & 24.5 & & $-\mathrm{OH}$ and $-\mathrm{Cl}$ \\
\hline DCF-TP 9 & 33.62 & 274.0237 & $\mathrm{C}_{14} \mathrm{H}_{8} \mathrm{NO}_{3} \mathrm{Cl}$ & 11 & 10.4 & & $+\mathrm{OH}$ and $-\mathrm{Cl}$ \\
\hline DCF-TP 10 & 32.96 & 264.0414 & $\mathrm{C}_{13} \mathrm{H}_{10} \mathrm{NO}_{3} \mathrm{Cl}$ & 9 & 3.0 & $246\left(\operatorname{loss} \mathrm{H}_{2} \mathrm{O}\right)$ & \\
\hline DCF-TP 11 & 32.50 & 294.0053 & $\mathrm{C}_{14} \mathrm{H}_{9} \mathrm{NO}_{2} \mathrm{Cl}_{2}$ & 10 & 10.3 & $245 / 247$ & \\
\hline \multirow[t]{2}{*}{ DCF-TP 12} & 31.50 & 258.0309 & $\mathrm{C}_{14} \mathrm{H}_{8} \mathrm{NO}_{2} \mathrm{Cl}$ & 11 & 2.8 & $\begin{array}{l}230.03 / 232.03 \\
260.0 / 262.03\end{array}$ & $-\mathrm{Cl}+\mathrm{OH}$ \\
\hline & & & & & & 197 & \\
\hline DCF-TP 12 & 30.90 & 278.0573 & $\mathrm{C}_{14} \mathrm{H}_{12} \mathrm{NO}_{3} \mathrm{Cl}$ & 9 & 2.0 & $248\left(\operatorname{loss} \mathrm{H}_{2} \mathrm{O}\right)$ & \\
\hline DCF-TP 13 & 30.70 & 266.0093 & $\mathrm{C}_{13} \mathrm{H}_{8} \mathrm{NOCl}_{2}$ & 9 & 15.4 & & \\
\hline DCF-TP 14 & 30.70 & 258.0309 & $\mathrm{C}_{14} \mathrm{H}_{8} \mathrm{NO}_{2} \mathrm{Cl}$ & 11 & 2.8 & & \\
\hline DCF-TP 15 & 30.20 & 298.0050 & $\mathrm{C}_{13} \mathrm{H}_{9} \mathrm{NO}_{3} \mathrm{Cl}_{2}$ & 9 & 6.0 & & \\
\hline \multirow[t]{2}{*}{ DCF-TP 17} & 29.10 & 312.0156 & $\mathrm{C}_{14} \mathrm{H}_{11} \mathrm{NO}_{3} \mathrm{Cl}_{2}$ & 9 & 10.3 & $\begin{array}{l}\text { Position isomer } \\
\text { Of DCF- TP16 }\end{array}$ & $\mathrm{DCF}-\mathrm{OH}$ \\
\hline & & & & & & $\begin{array}{l}\text { [Check } 246.030 \\
\text { coeluting frag?] }\end{array}$ & \\
\hline \multirow[t]{2}{*}{ DCF-TP 18} & 28.10 & 260.0452 & $\mathrm{C}_{14} \mathrm{H}_{10} \mathrm{NO}_{2} \mathrm{Cl}$ & 10 & 8.0 & $\begin{array}{l}\text { Frag @ } \\
232.05 / 234.05\end{array}$ & Dechlorination \\
\hline & & & & & & 196/197/198 & \\
\hline DCF-TP 19 & 27.60 & 278.0546 & $\mathrm{C}_{14} \mathrm{H}_{12} \mathrm{NO}_{3} \mathrm{Cl}$ & 9 & 11.7 & & \\
\hline DCF-TP 20 & 27.30 & 246.0295 & $\mathrm{C}_{13} \mathrm{H}_{8} \mathrm{NO}_{2} \mathrm{Cl}$ & 10 & 8.7 & & $-\mathrm{Cl}-\mathrm{ClH}_{2}$ \\
\hline DCF-TP 21 & 27.10 & 264.0398 & $\mathrm{C}_{13} \mathrm{H}_{10} \mathrm{NO}_{3} \mathrm{Cl}$ & 9 & 9.1 & & \\
\hline \multirow[t]{3}{*}{ DCF-TP 22} & 27.00 & 278.0567 & $\mathrm{C}_{13} \mathrm{H}_{10} \mathrm{NO}_{3} \mathrm{Cl}$ & 9 & 4.1 & $\begin{array}{l}\text { Water loss } \\
(\mathrm{m} / \mathrm{z} 260)\end{array}$ & \\
\hline & & & & & & Coeluting $\mathrm{m} / \mathrm{z}$ & \\
\hline & & & & & & $\begin{array}{l}\text { 294.0037. Need to } \\
\text { check MS/MS }\end{array}$ & \\
\hline DCF-TP 23 & 26.40 & 260.0441 & $\mathrm{C}_{14} \mathrm{H}_{10} \mathrm{NO}_{2} \mathrm{Cl}$ & 10 & 12.3 & & Dechlorination \\
\hline DCF-TP 24 & 24.70 & 280.0237 & $\mathrm{C}_{14} \mathrm{H}_{11} \mathrm{NOCl}_{2}$ & 9 & 19.1 & Water loss & $\begin{array}{l}\text { Low int. (Check } \\
\text { SPE vial) }\end{array}$ \\
\hline DCF-TP 25 & 23.80 & 244.0517 & $\mathrm{C}_{14} \mathrm{H}_{10} \mathrm{NOCl}$ & 10 & 2.8 & & Low int. \\
\hline DCF-TP 26 & 23.70 & 294.0500 & $\begin{array}{l}\mathrm{C}_{14} \mathrm{H}_{12} \mathrm{NO}_{4} \mathrm{Cl} \\
\mathrm{C}_{15} \mathrm{H}_{13} \mathrm{NOCl}_{2} \text { (2nd option) }\end{array}$ & 9 & 9.4 & Water loss & $\begin{array}{l}\text { To be confirmed } \\
\text { Elemental comp }\end{array}$ \\
\hline
\end{tabular}

HPLC conditions: Gradient elution with following eluents A: $0.1 \%$ formic acid; B: acetonitrile, $0.1 \%$ formic acid. Flow rate: $0.5 \mathrm{~mL} / \mathrm{min}$. Gradient: 0 $3 \mathrm{~min}$ : $30 \% \mathrm{~B}$, then from 3 to $10 \mathrm{~min}, 30-40 \%$, then $10-40 \mathrm{~min}$, from 40 to $65 \%$, then $40-45 \mathrm{~min}$, from 65 to $100 \%, 45-46,100 \%$, then $46-47$, from 100 to $30 \%$ (equilibration) and from 47 to $55 \mathrm{~min}, 30 \%$ (initial mobile phase composition for equilibration). IT-TOF MS conditions: full-scan acquisition with polarity switching; mass range: $\mathrm{m} / \mathrm{z} 150-1000$; ion trap accumulation time: $50 \mathrm{~ms}$

$k=(3.1 \pm 0.2) \times 10^{9} \mathrm{M}^{-1} \mathrm{~s}^{-1}$ (see inset in Fig. 9). This value is two times larger, than that one reported by other authors [Yu et al. 2013]. The last spectrum (Fig. 9, curve C) recorded $200 \mu \mathrm{s}$ after pulse shows the shoulder of absorption at $325 \mathrm{~nm}$, infers that product of [diclofenac $\left.{ }^{*}\right]^{-}$decay absorbs at shorter wavelength. 


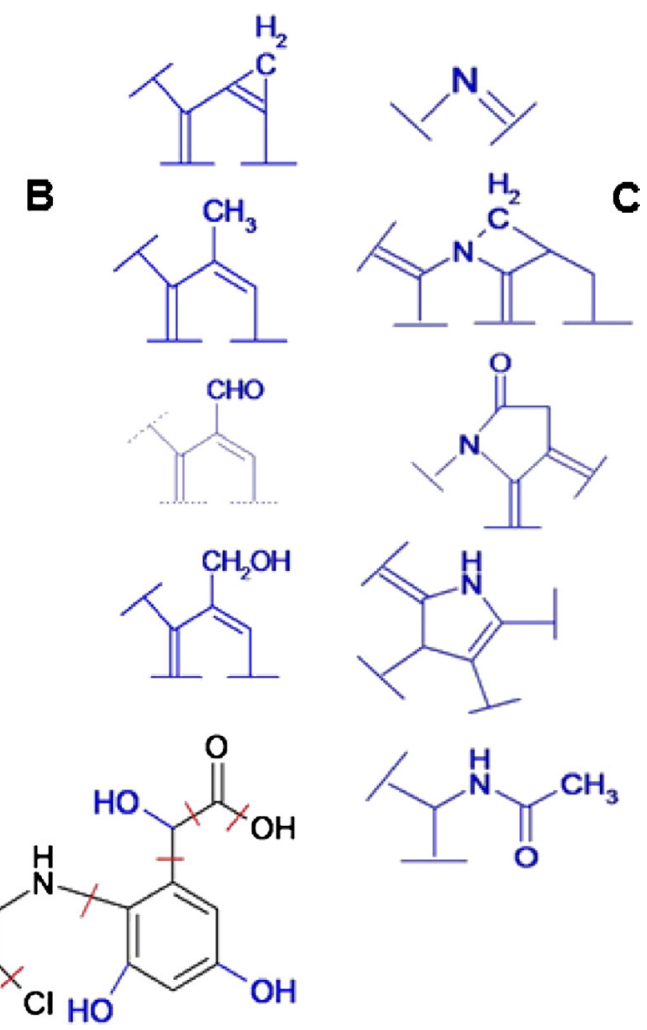

Fig. 7 Schematic illustration of structural changes obtained in products of radiolytic degradation of diclofenac elucidated from obtained LC/MS data. a Breaking of bonds in DCF molecule showed by red bars, and positions of new substitute hydroxyl groups in DCF molecule marked in blue. b Structural changes of phenylacetic acid group of DCF molecule found among the products of DCF degradation. c Structural changes in part of DCF molecule surrounding amino group, which are deducted from identified products of DCF degradation

\section{Figures of merit of radiolytic decomposition}

The kinetic characteristics of chemical reaction is determined by the order of reaction and the values of the reaction rate constants, however, the effectiveness of the irradiation processes is commonly expressed in $G$ value, the value of dose constant and the dose required for 50 or $90 \%$ decomposition of the irradiated solute [Mincher and Curry 2000]. $G$ value (expressed in SI units in $\mu \mathrm{M} \mathrm{J}^{-1}$ ), reported also as radiolytic or radiochemical yield, is defined as number of molecules formed or decomposed in the solution as result of absorbing $100 \mathrm{eV}$ energy, and can be calculated at given absorbed dose using Eq. (9) [Kurucz et al. 1991]:

$G=\left[\left(C_{0}-C_{\mathrm{D}}\right) N_{\mathrm{A}}\right] / D K_{\mathrm{f}}$

where $C_{0}$ is initial concentration of analyte $[\mathrm{M}], C_{\mathrm{D}}$ is the concentration of analyte [M] after absorbing dose $D$ [Gy], $N_{\mathrm{A}}$ is the Avogadro number $6.02 \times 10^{23}$, and $K_{\mathrm{f}}$ is the conversion factor from Gy to $100 \mathrm{eV} \mathrm{L}^{-1}$, which is equal to $6.24 \times$ $10^{17}$. The basic limitation of its usefulness is that it is usually concentration dependent, and therefore, very often rather the initial values $G_{0}$ are calculated for the smallest applied dose near the beginning of the irradiation in function of absorbed dose. Although it is commonly reported in applied radiolysis, it is not considered as very useful for predicting the dose required to decompose the examined analyte.

Another factor, the observed dose constant $d$, determines the decomposition rate as function of the absorbed dose of radiation. It is calculated as the slope of the plot of $-\ln \left(C_{\mathrm{D}} /\right.$ $C_{0}$ ) vs. absorbed dose (Gy), and is considered as more accurate than $G_{0}$ because it uses all the data from the irradiation procedure. The values of $d$ are employed for determination of
Fig. 8 Absorption spectra recorded in $\mathrm{N}_{2} \mathrm{O}$-saturated aqueous DCF solution in pulse radiolysis measurements. Spectra were collected after following time delays squares $0.12 \mu \mathrm{s}$; circles $0.8 \mu \mathrm{s} ;$ diamonds $16 \mu \mathrm{s}$, triangles $0.5 \mathrm{~ms}$. Inset SternVolmer plot of the absorption growth at $\lambda=370 \mathrm{~nm}$

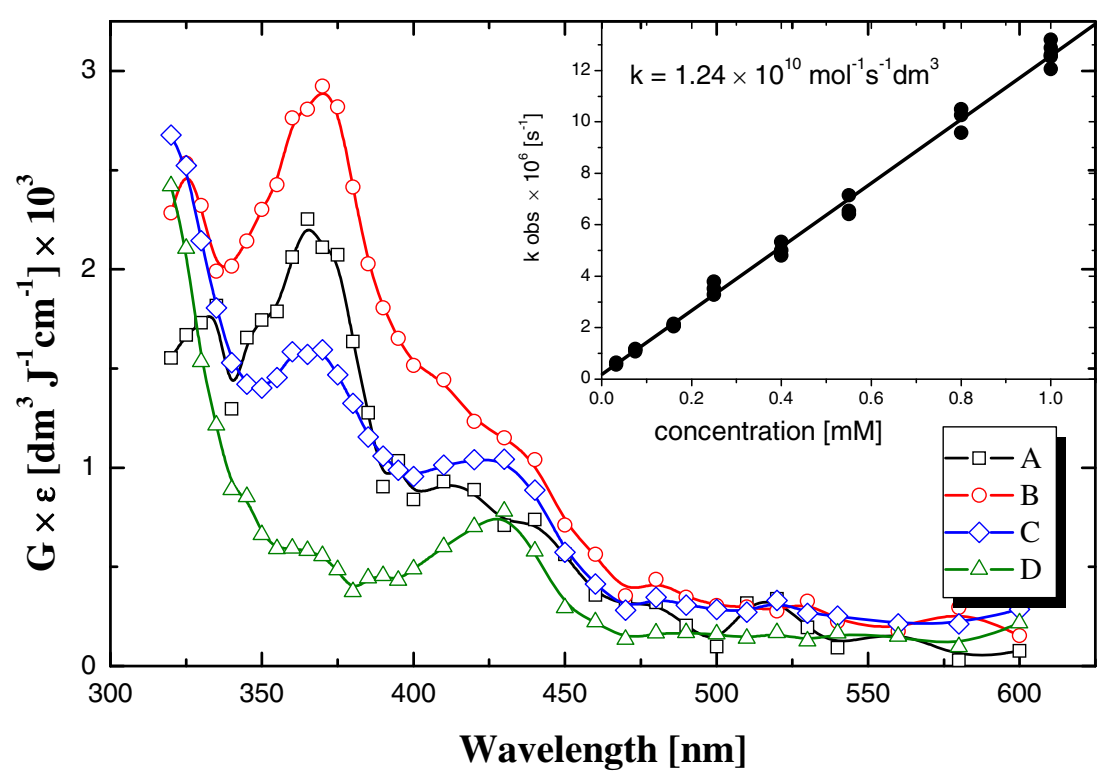


Fig. 9 Absorption spectra recorded in Ar-saturated aqueous DCF solution containing $0.5 \mathrm{mM}$ tert-butanol in pulse radiolysis measurements. Spectra taken after following time delays: squares $120 \mathrm{~ns}$; circles 1.6 us; triangles $200 \mu$ s. Inset Stern-Volmer plot of the absorption decay at $\lambda=$ $700 \mathrm{~nm}$

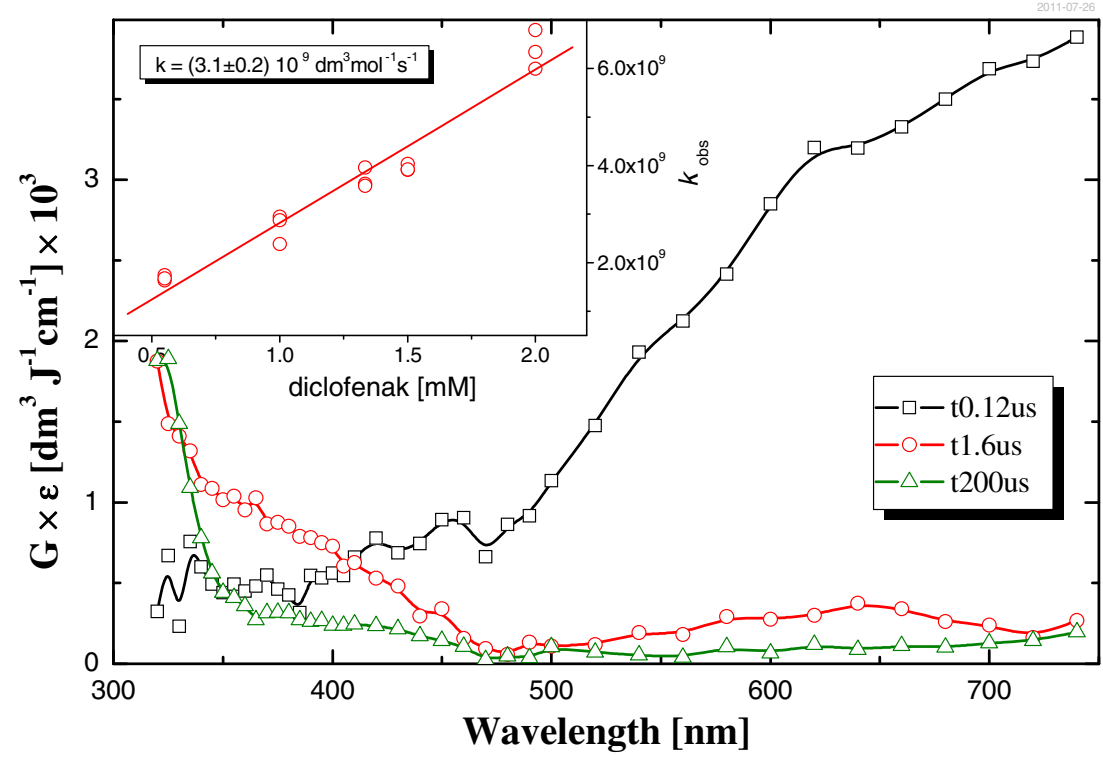

$90 \%$ decomposition value as follows: $D_{0.90}=(\ln 10) / d$ [Cooper et al. 1993].

The calculated values of those figures of merit $G_{\mathrm{o}}, d$, and $D_{0.9}$ for DCF are compared in Table 4 with those obtained for three other examined analytes, and also with those calculated for radiolytic decomposition of a commonly used pesticide parathion (at given initial concentration values). In all cases, they concern the yield of radiolytic decomposition under oxidizing conditions, in air-saturated solutions without any additional pretreatment, where hydroxyl radicals are predominating reactive species, with simultaneous presence of $\mathrm{O}_{2}{ }^{--}$and $\mathrm{HO}_{2}{ }^{-}$radicals according to Eqs. (4) and (5). For comparison, there are also values of rate constants shown for the reactions of a given analyte with the hydroxyl radicals (with bias regarding different published values). Those rate constant values are of the same order of magnitude for considered species, and the same can be said about $G_{\mathrm{o}}$ values, which were calculated for the smallest absorbed dose. Evidently, larger span of calculated values can be noticed for dose constant and $D_{0.9}$ values, which are the most convincing quantities proving information about the yield of radiolytic decomposition process. Those values are similar for DCF, ibuprofen, and bisphenol A, while larger doses are required for decomposition of carbamazepine, and especially parathion. As shown, e.g., for polychlorinated biphenyls (Mincher et al. 1998], values of dose constant, and then also $D_{0.9}$ are also concentration dependent, and must be evaluated for particular concentration level of pollutant.

\section{Conclusions}

Up to now, all data referring degradation diclofenac using ionizing radiation were obtained in pure aqueous solutions [Liu et al. 2011, Homolok et al. 2011, Yu et al. 2013], while in this study, the yield of degradation was evaluated also in samples of river water and hospital waste. Present studies were focused mostly on the radiolytic decomposition of diclofenac, but in measurements in real samples also additionally carbamazepine, ibuprofen also industrial pollutant bisphenol A were examined. Compared to previous studies, the conducted measurements in real samples were carried at concentration levels, close to those reported earlier in environmental samples. For DCF using the pulse-radiolysis method,

Table 4 Figures of merit for the radiolytic decomposition of examined pharmaceuticals, pesticide parathion and bisphenol A using gamma radiation

\begin{tabular}{llllll}
\hline Compound & $\begin{array}{l}\text { Examined } \\
\text { concentration, } \mathrm{mg} / \mathrm{L}\end{array}$ & $\begin{array}{l}\text { Rate constant for reaction } \\
\text { with }{ }^{\circ} \mathrm{OH}, \mathrm{M}^{-1} \mathrm{~s}^{-1}\end{array}$ & $\begin{array}{l}\text { Radiolytic yield } \mathrm{G}_{\mathrm{o}}, \mu \mathrm{M} \mathrm{J}^{-1} \\
\text { (calculated at given absorbed } \\
\text { dose, } \mathrm{kGy})\end{array}$ & $\begin{array}{l}\text { Dose constant, } \mathrm{kGy}^{-1} \\
D_{0.9} \text { Dose required for } \\
90 \% \text { decomposition, } \mathrm{kGy}\end{array}$ \\
\hline Diclofenac & 10 & $12.4 \times 10^{9}$ (this work) & $0.147(0.2)$ & 6.02 & 7.02 \\
Ibuprofen & 10 & 6.7 to $10 \times 10^{9}$ & $0.163(0.2)$ & 4.37 & 0.38 \\
Carbamazepine & 10 & $(2.0$ to 9.7$) \times 10^{9}$ & $0.109(0.2)$ & 7.19 & 0.53 \\
Bisphenol A & 6.9 & $6.9 \times 10^{9}$ & $0.141(0.1)$ & 1.76 & 0.32 \\
Parathion & 15 & $(4.2$ to 9.7$) \times 10^{9}$ & $0.136(0.2)$ & 1.31 \\
\hline
\end{tabular}


the rate constants for reactions with hydroxyl radical $(1.24 \pm$ $0.02) \times 10^{10} \mathrm{M}^{-1} \mathrm{~s}^{-1}$ and solvated electron $(3.1 \pm 0.2) \times$ $10^{9} \mathrm{M}^{-1} \mathrm{~s}^{-1}$ were determined, showing that both the oxidative and reductive processes in radiolytic decomposition of DCF take place in irradiated diluted aqueous solutions of DCF. The conducting of DCF radiolytic decompositions, however, is more efficient in oxidative conditions. The radiolytic decomposition with required doses of gamma radiation from ${ }^{60} \mathrm{Co}$ sources takes about $4 \mathrm{~min}$, (when dose rate is $4.8 \mathrm{kGy} / \mathrm{h}$ ) and compared to other developed methods are much quicker. The same processes carried out using electron beam irradiation could be practically considered as instantaneous.

In this study, also the influence of the absorbed dose magnitude ( 100 to $250 \mathrm{~Gy}$ ) for the decomposition of selected other pollutants in river water was monitored. Under employed conditions, diclofenac and ibuprofen were completely destroyed with the use 100 Gy absorbed dose. Carbamazepine and bisphenol A, however, were still present even after irradiation with the absorbed dose $250 \mathrm{~Gy}$. In the case of waste from hospital, the decomposition of carbamazepine and bisphenol A was more difficult. After $500 \mathrm{~Gy}$, these compounds have not been successfully destroyed.

The essential complement of chemical control of decomposition pharmaceuticals during gamma decomposition is toxicity monitoring. In two earlier works [Homolk et al. 2011, Yu et al. 2013] for toxicity monitoring during the process used only bioluminescence test Microtox was employed. In our study, three different tests was applied, Microtox, Thamnotoxkit, and Spirotx. This allows to answer the question what is the authentic impact of degradation products on the environment.

Based on our study, it can be concluded that the HPLC method with UV detection and the appropriate preconcentration procedure can be used for the determination of pharmaceuticals and bisphenol A in water and wastewater at concentration level micrograms per liter. We expect that with the use of larger doses, a complete decomposition of more resistant compounds carbamazepine and bisphenol A can be also achieved.

Open Access This article is distributed under the terms of the Creative Commons Attribution 4.0 International License (http:// creativecommons.org/licenses/by/4.0/), which permits unrestricted use, distribution, and reproduction in any medium, provided you give appropriate credit to the original author(s) and the source, provide a link to the Creative Commons license, and indicate if changes were made.

\section{References}

Achilleos A, Hapeshi E, Xekoukoulotakis NP, Mantzvinos D, FattaKassinos D (2010) Factors affecting diclofenac decomposition in water by $\mathrm{UV}-\mathrm{A} / \mathrm{TiO}_{2}$ photocatalysis. Chem Eng J 161:53-59

Agiunaco A, Beltran FJ, Garcia-Araya JF, Oropesa A (2012) Phlotocatalytic ozonation to remove the pharmaceutical diclofenac from water: influence of variables. Chem Eng J 189-190:275-282
Aguera A, Perez-Estrada LA, Ferrer I, Thurman EM, Malato S, Fernandez-Alba AR (2005) Application of time-of-flight mass spectrometry to the analysis of photo-transformation products of diclofenac in water under natural sunlight. J Mass Spectrom 40: 908-915

Bae S, Kim D, Lee W (2013) Degradation of diclofenac by pyrite catalyzed Fenton oxidation. Appl Catal B Environ 134-135:93-102

Bartels P, von Tümpling JW (2007) Solar irradiation influence on the decomposition process of diclofenac in surface waters. Sci Total Environ 374:143-155

Basfar AA, Mohammed KA, Al-Abduly AJ, Al-Shahrani AA (2009) Radiolytic degradation of atrazine aqueous solution containing humic substances. Ecotox Environ Safety 72:948-953

Bobrowski K (2005) Free radicals in chemistry, biology and medicine: contribution of radiation chemistry. Nukleonika 50:67-76

Boxal ABA, Sinclair CJ, Fenner K, Kolpin D, Maund SJ (2004) When synthetic chemicals degrade in the environment. Environ Sci Technol 38:368A-375A

Buser HR, Poiger T, Müller MD (1998) Occurrence and fate of the pharmaceutical drug diclofenac in surface waters: rapid photodegradation in a lake. Environ Sci Technol 32:3449-3456

Buxton GV, Sdtuart CR (1995) Re-evaluation of the thiocyanate dosimeter for pulse radiolysis. J Chem Soc Farady Trans 91:279-281

Buxton G, Greenstock C, Helman WP, Ross AB (1988) Critical review of rate constants for reactions of hydrated electrons, hydrogen atoms and hydroxyl radicals $\left(\mathrm{OH} / \mathrm{O}^{-}\right)$in aqueous solution. J Phys Chem Ref Data 17:513-886

Calza P, Sakkas VA, Medana C, Baiocchi C, Dimou A, Pelizzetti E, Albanis T (2006) Photocatalytic degradation study of diclofenac over aqueous $\mathrm{TiO}_{2}$ suspension. Appl Catal B Environ 67:197-205

Carlsson CJ, Alvan AK, Bergman G, Kuhler KT (2006) Are pharmaceuticals potent environmental pollutants? Part I: environmental risk assessments of selected active pharmaceutical ingredients. Sci Total Environ 364:67-87

Cooper JW, Cadavid E, Nickelsen GM, Lin K, Kurucz NC, Waite DT (1993) Removing THMs from drinking water using high-energy electron-beam irradiation. J Am Water Works Assoc 85:106-112

Daughton CG, Ternes TA (1999) Pharmaceuticals and personal care products in the environment. Environ Health Pers 107:907-938

Dobrin D, Bradu C, Magureanu M, Mandache NB, Parvulescu VI (2013) Degradation of diclofenac in water using a pulsed corona discharge. Chem Eng J 234:389-396

Farre M, Petrovic M, Barcelo D (2007) Recently developed GC/MS and LC/MS methods for determining NSAIDs in water samples. Anal Bioanal Chem 387:1203-1214

Fatta-Kassinos D, Meric S, Nikolaou A (2011) Pharmaceutical residues in environmental waters and wastewater: current state of knowledge and future research. Anal Bioanal Chem 399:251-275

Fent K, Weston AA, Caminada D (2006) Ecotoxicology of human pharmaceuticals. Aquat Toxicol 76:122-159

Ferrari B, Paxeus N, Lo Giudice R, Pollio A, Garric J (2003) Ecotoxicological impact of pharmaceuticals found in treated wastewaters: study of carbamazepine, clofibric acid, and diclofenac. Ecotox Environ Safety 55:359-370

Finkbeiner P, Franke M, Anschuetz F, Ignaszak A, Stelter M, Braeutigam $\mathrm{P}$ (2015) Sonoelectrochemical degradation of the anti-inflammatory drug diclofenac in water. Chem Eng J 272:214-222

Getoff N (1996) Radiation-induced degradation of water pollutantsstate of the art. Radiat Phys Chem 47:581-593

Hartmann J, Bartekls P, Mau U, Witter M, von Tümpling W, Hofmann J, Nietz-Schmann E (2008) Degradation of the drug diclofenac in water by sonolysis in presence of catalysts. Chemosphere 70:453-461

Hofmann J, Freier U, Wecks M, Hohmann S (2007) Degradation of diclofenac in water by heterogeneous catalytic oxidation with $\mathrm{H}_{2} \mathrm{O}_{2}$. Appl Catal B Environ 70:447-451 
Homolok R, Takacs E, Wojnarovits L (2011) Elimination of diclofenac from water using irradiation technology. Chemosphere 85:603-608

Houeto P, Carton A, Guerbet M, Mauclaire A-C, Gatignol C, Lechat P, Masset D (2012) Assessment of the health risk related to the presence of drug residues in water for human consumption: application to carbamazepine. Reg Toxicol Pharm 62:41-48

Ikehata K, Naghashkhar NJ, El-Din MG (2006) Degradation of aqueous pharmaceuticals by ozonation and advanced oxidation processes: a review. Ozone Sci Eng 28:353-414

Johnson AC, Dumont E, Williams RJ, Oldenkamp R, Cisowska I, Sumpter JP (2013) Do concentrations of ethinylestradiol, estradiol, and diclofenac in European rivers exceed propose EU environmental quality standards? Environ Sci Technol 47:12297-12304

Jones OA, Lester JN, Voulvoulis N (2005) Pharmaceuticals: a threat to drinking water? Trends Biotechnol 23:163-167

Kimura A, Osawa AM, Taguchi M (2012) Decomposition of persistent pharmaceuticals in waste water by ionizing radiation. Radiat Phys Chem 81:1508-1512

Kumar A, Xagoraraki I (2010) Pharmaceuticals, personal care products and endocrine-disrupting chemicals in U.S. surface and finished drinking waters: a proposed ranking system. Sci Total Environ 408:5972-5989

Kümmerer K (Ed.) (2008) Pharmaceuticals in the environment: sources, fate, effects and risks. Springer-Verlag, Heidelberg Berlin

Kurucz CN, Waite TD, Cooper WJ, Nickelsen MG (1991) High energy electron beam irradiation of water, wastewater and sludge. In: Lewnes J, Becker M (eds) Advances in Nuclear Science and Technology, vol 22. Plenum Press, New York, pp 1-42

Langford KH, Thomas KV (2009) Determination of pharmaceutical compounds in hospital effluents and their contribution to wastewater treatment works. Environ Intern 35:766-770

Liu Q, Luo X, Zheng Z, Zheng B, Zhang J, Zhao Y, Yang X, Wang L (2011) Factors that have an effect on degradation of diclofenac in aqueous solution by gamma ray irradiation. Environ Sci Pollut Res 18:1243-1252

Luo Y, Guo W, Ngo HH, Nghiem LD, Hai FI, Zhang J, Liang S, Wang $\mathrm{XC}$ (2014) A review on the occurrence of micropollutants in the aquatic environment and their fate and removal during wastewater treatment. Sci Total Environ 473-474:619-641

Martinez C, Canle LM, Fernandez MI, Santaballa JA, Faria J (2011) Aqueous degradation of diclofenac by heterogeneous photocatalysis using nanostructured materials. Appl Catal B Environ 107:110 1189

Michael I, Achilleos A, Lambropoulou D, Ososorio Torrens V, Perez S, Petrovic M, Barcelo D, Fatta-Kassinos D (2014) Proposed transformation pathway and evolution profile of diclofenac and ibuprofen transformation products during (sono)photocatalysis. Appl Catalysis B Env 147:1015-1027

Mincher BJ (1998) Radiolysis of polychlorinated biphenyls in nonpolar solvents. In: Cooper WJ, Curry RD, O'Shea KE (eds) Environmental applications of ionizing radiation. John Wiley and Sons, New York (Chapter 16)

Mincher BJ, Curry RD (2000) Considerations for choice of a kinetic fig. of merit in process radiation chemistry for waste treatment. Appl Radiat Isoto 52:189-193

Mompelat S, Le Bot B, Thomas O (2009) Occurrence and fate of pharmaceutical products, from source to drinking water. Environ Intern $35: 803-814$

Naddeo V, Belgiorno V, Ricco D, Kassinos D (2009) Ultrasonic degradation, mineralization and detoxification of diclofenac in waters: Optimization of operating parameters. Ultrason Sonochem 16: 790-794

Naddeo V, Belgiorno V, Kassinos D, Mantzavinos D, Meric S (2010) Ultrasonic degradation, mineralization and detoxification of diclofenac in water: optimization of operating parameters. Ultrason Sonochem 17:179-185
Nałecz-Jawecki G, Sawicki J (1999) Spirotox — a new tool for testing the toxicity of volatile compounds. Chemisophere 38:3211-3218

Nie E, Yang M, Wang D, Yang X, Luo X, Zheng Z (2014) Degradation of diclofenac by ultrasonic irradiation: kinetic studies and degradation pathways. Chemosphere 113:165-170

Oaks JL, Gilbert M, Virani MZ, Watson RT, Meteyer CU, Rideout BA, Shivaprasad HL, Ahmed S, Chaudhry MJI, Arshad M, Mohamood S, Ali A, Khan AA (2004) Diclofenac residues as the cause of vulture population decline in Pakistan. Nature 427:630-633

OECD (2012) Pharmaceutical consumption. Chapter in "Health at a Glance Europe 2012. OECD Publishing. http://dx.doi.org/10.1787/ 9789264183896-38-en

Perez-Estrada LA, Maldonado MI, Gernjak W, Agüra A, Fernandez-Alba AR, Ballesteros MM, Malato S (2005a) Decomposition of diclofenac by solar driven photocatalysis at pilot plant scale. Catalysis Today 101:219-226

Perez-Estrada LA, Malato S, Gernjak W, Aguera A, Thurman EM, Ferrer I, Fernandez-Alba AR (2005b) Photo-Fenton degradation of diclofenac: identification of main intermediates and degradation pathway. Environ Sci Technol 39:8300-8306

Ravina M, Campanella L, Kiwi J (2002) Accelerated mineralization of the drug diclofenac via Fenton reactions in a concentric photo-reactor. Water Res 36:3553-3560

Rizzo L, Meric S, Kassinos D, Guid AM, Russo F, Belgiorno V (2009) Degradation of diclofenac by $\mathrm{TiO}_{2}$ photocatalysis: UV absorbance kinetics and process evaluation through a set of toxicity bioassays. Water Res 43:979-988

Sanchez-Polo M, Lopez-Penalver J, Prados-Joya G, Ferro-Garcia MA, Rivera-Ytrilla J (2009) Gamma-irradiation of pharmaceutical compounds, nitroimidazoles, as a new alternative for water treatment. Water Res 43:4028-4036

Santos JL, Aparicio I, Alonso E (2007) Occurrence and risk assessment of pharmaceutically active compounds in wastewater treatment plants. A case study: Seville city (Spain). Environ Intern 33:596601

Schulman LJ, Sargent EV, Numann BD, Faria EC, Dolan DG, Wargo JP (2002) A human health risk assessment of pharmaceuticals in the aquatic environment. Human Ecol Risk Ass 8:657-687

Schwaiger J, Ferling H, Mallow U, Wintermayr H, Negele RD (2004) Toxic effects of non-steroidal anti-inflammatory drug diclofenac Part I: histopathological alterations and bioaccumulation in rainbow trout. Aquat Toxicol 68:141-150

Shin H, Oh J (2012) Simultaneous determination of non-steroidal antiinflammatory drugs in river water by gas chromatography-mass spectrometry. J Sep Sci 35:541-547

Snyder SA (2008) Occurrence, treatment, and toxicological relevance of EDCs and pharmaceuticals in water. Ozone Sci Technol 30:65-69

Song W, Cooper WJ, Mezyk J, Greaves SP, Peake BM (2008) Free radical destruction of $\beta$-blockers in aqueous solution. Environ Sci Technol 42:1256-1261

Stumm-Zollinger E, Fair GM (1965) Biodegradation of steroid hormones. J Water Poll Control Fed 37:1506-1510

Suzuki T, Nakagawa Y, Takano I, Yaguchi K, Yasuda K (2004) Environmental fate of bisphenol $\mathrm{A}$ and its biological metabolites in river water and their xeno-estrogenic activity. Environ Sci Technol 38:2389-2396

Tabak HH, Brunch RL (1970) Steroid hormones as water pollutants. Develop Ind Microbiol 11:367-376

Trojanowicz M, Bojanowska-Czajka A, Kciuk G, Bobrowski K, Gumiela M, Koc A, Nałęcz-Jawecki G, Torun M, Ozbay DS (2012) Application of ionizing radiation in decomposition of selected organic pollutants in waters. Eur Water 39:15-26

Vogna D, Marotta R, Napolitano A, Andreozzi R, d'Ischia M (2004) Advanced oxida-tion of the pharmaceutical drug diclofenac with $\mathrm{UV} / \mathrm{H}_{2} \mathrm{O}_{2}$ and ozone. Water Res 38:414-422 
Wang Y, Liu H, Liu G, Xie Y, Ni T (2015) Oxidation of diclofenac with chlorine dioxide in aquatic environments: influences of different nitrogenous species. Environ Sci Pollut Res 22:9449-9456

Yu H, Nie E, Xu J, Yan S, Cooper WJ, Song W (2013) Degradation of diclofenac by advanced oxidation and reduction process: kinetic studies, degradation pathways and toxicity assessments. Water Res 47:1909-1918
Zhang Y, Geissen SU, Gal C (2008) Carbamazepine and diclofenac: removal in waste-water treatment plants and occurrence in water bodies. Chemosphere 73:1151-1161

Zhao X, Hou Y, Liu H, Qiang Z, Qu J (2009) Electrooxidation of diclofenac at boron doped diamond: kinetics and mechanism. Electrochim Acta 54:4172-4179

Zwiener C, Frimmel FH (2000) Oxidative treatment of pharmaceuticals in water. Water Res 34:1881-1885 